\title{
Strain response and energy dissipation of floating saline ice under cyclic compressive stress
}

\author{
Mingdong Wei ${ }^{1}$, Arttu Polojärvi ${ }^{1}$, David M. Cole ${ }^{2}$, and Malith Prasanna ${ }^{1}$ \\ ${ }^{1}$ School of Engineering, Department of Mechanical Engineering, Aalto University, P.O. Box 14100, 00076 Aalto, Finland \\ ${ }^{2}$ ERDC-CRREL (Ret.), 72 Lyme Rd., Hanover, NH 03768, USA
}

Correspondence: Arttu Polojärvi (arttu.polojarvi@aalto.fi)

Received: 16 January 2020 - Discussion started: 7 February 2020

Revised: 13 July 2020 - Accepted: 27 July 2020 - Published: 4 September 2020

\begin{abstract}
Understanding the mechanical behavior of sea ice is the basis of applications of ice mechanics. Laboratoryscale work on saline ice has often involved dry, isothermal ice specimens due to the relative ease of testing. This approach does not address the fact that the natural sea ice is practically always floating in seawater and typically has a significant temperature gradient. To address this important issue, we have developed equipment and methods for conducting compressive loading experiments on floating laboratory-prepared saline ice specimens. The present effort describes these developments and presents the results of stress-controlled sinusoidal cyclic compression experiments. We conducted the experiments on dry, isothermal $\left(-10^{\circ} \mathrm{C}\right)$ ice specimens and on floating-ice specimens with a naturally occurring temperature gradient. The experiments involved ice salinities of 5 and $7 \mathrm{ppt}$, cyclic stress levels ranging from $0.04-0.12$ to $0.08-0.25 \mathrm{MPa}$ and cyclic loading frequencies of 0.001 to $1 \mathrm{~Hz}$. The constitutive response and energy dissipation under cyclic loading were successfully analyzed using an existing physically based constitutive model for sea ice. The results highlight the importance of testing warm and floatingice specimens and demonstrate that the experimental method proposed in this study provides a convenient and practical approach to perform laboratory experiments on floating ice.
\end{abstract}

\section{Introduction}

Climate change has led to an increased interest in polar sea areas and in ice behavior since accurate predictions of the evolution of the ice conditions are crucial for modeling the future climate. Warming climate has also resulted in a search for more efficient marine transit routes, production of offshore wind power, industrial operations related to extraction of hydrocarbons, and even tourism in the north (Gagne et al., 2015; Serreze and Stroeve, 2015; Kern et al., 2019). Structural loads due to sea ice make these activities challenging. In-depth understanding of the physical and mechanical properties of sea ice is required to develop tools for modeling future ice conditions and the related ice-ice and ice-wave interaction problems as well as to design safe and sustainable offshore structures (Dempsey, 2000; Feltham, 2008; Herman et al., 2019a, b; Lu and Løset, 2018; Lu et al., 2018; Ranta et al., 2017, 2018a, b; Tuhkuri and Polojärvi, 2018; Polojärvi et al., 2015; Voermans et al., 2019; Cheng et al., 2019; Li et al., 2015).

This paper studies the mechanical behavior of laboratoryprepared saline ice specimens under cyclic loading. This type of loading occurs in wave-ice and some ice-ice and icestructure interaction problems - all important in the changing polar environment. For example, warming climate causes an increase in the amount of open water and broken ice fields, which strengthens the impact of waves on sea ice. From the perspective of pure-ice mechanics and modeling of ice, the cyclic loading experiments yield information on the elastic and viscoelastic components of strain and their dependence on the physical or microstructural characteristics of the ice. The cyclic loading tests also give insight into the fatigue of ice (Haskell et al., 1996; Bond and Langhorne, 1997; Langhorne et al., 1998; Mellor and Cole, 1981; Murdza et al., 2019; Schulson and Paul, 2009; Iliescu et al., 2017; Iliescu and Schulson, 2002).

Cyclic loading experiments on freshwater ice have been performed since the '40s (Kartashkin, 1947; Mellor and 
Cole, 1981) and on saline ice since the '80s (Tabata and Nohguchi, 1980; Cole, 1995; Cole and Durell, 1995; Cole et al., 1998). Cole and Durell (1995) studied the effects of temperature (from -5 to $-50{ }^{\circ} \mathrm{C}$ ), cyclic stress amplitude (from 0.1 to $0.8 \mathrm{MPa}$ ) and loading frequency (from $10^{-3}$ to $1 \mathrm{~Hz}$ ) on the response of laboratory-grown saline ice; the ice response was revealed to be sensitive to variations in these factors. Cole et al. (1998) investigated the response of columnar first-year sea ice to cyclic loading and found that the elastic, anelastic and viscous strains varied according to the relation between the loading and preferred $c$ axis directions of the specimens. More recently, Heijkoop et al. (2018) conducted strain-controlled cyclic compression tests on sea ice to ascertain the variation in storage and loss compliances versus frequency. All of this earlier work has been performed using isothermal, dry specimens.

An often-overlooked issue in laboratory-scale experimentation is that most sea ice problems involve ice that is floating on water. Floating ice commonly has a through-thickness temperature gradient, resulting in a through-thickness gradient in its mechanical properties. The latter point is important to address in experimentation and modeling. The temperature gradient is implicitly taken into account when performing in situ experiments on floating ice (Langhorne et al., 2015; Smith et al., 2015; Wongpan et al., 2018). The cost of in situ experimental campaigns, however, is high, and the experiments often require specially designed loading devices (Vincent and Dempsey, 1999; Dempsey et al., 1999, 2018; Cole and Dempsey, 2004). Consequently, the relatively low costs and convenience of laboratory-scale work motivate the development of viable methods for laboratory-scale experiments on floating ice. Such experiments can be used, for example, for thorough validation of material models aiming to account for the temperature gradient in ice.

In the study presented here, stress-controlled sinusoidal cyclic compression experiments were performed on laboratory-grown, nonoriented columnar saline ice specimens floating on salt water and repeated on dry, isothermal $\left(-10^{\circ} \mathrm{C}\right)$ specimens. The dry experiments were conducted to validate the performance of our newly developed testing apparatus and experimental methods under commonly used test conditions. Moreover, the results provide a reference of the different mechanical behavior of floating ice from that of the ice under such conditions. The varied parameters were the ice salinity, cyclic stress amplitude and mean stress level, and the frequency of cyclic loading. The results are comprehensively analyzed and discussed and are shown to compare favorably with the predictions of an existing physically based constitutive model (Cole, 1995). Techniques and observations yielding increased insight of the behavior of sea ice in its natural conditions are introduced; insight on rather warm floating ice is important as future sea ice is expected to be on average warmer than now (Boe et al., 2009; Blockley and Peterson, 2018; Ridley and Blockley, 2018).
The paper is organized as follows. Section 2 describes the specimen preparation, the experimental setup and the matrix of experimental variables. Section 3 presents the results from the experiments. Section 4 addresses constitutive modeling, Sect. 5 discusses our findings with references to earlier work, and Sect. 6 gives our conclusions.

\section{Laboratory experiments of saline ice under cyclic loading}

\subsection{Saline ice specimen preparation and characterization}

The ice was grown in the cold room of the Department of Mechanical Engineering, Aalto University, using a tank with dimensions of $1.15 \mathrm{~m} \times 1.15 \mathrm{~m} \times 0.98 \mathrm{~m}$ (width $\times$ length $\times$ depth) and meltwater salinities of 24 and 34 ppt. Rigid foam insulation was placed on the sides and bottom of the tank, and heating cables were placed around the bottom perimeter to inhibit freezing from the structural members of the tank. Additionally, a hose for draining excess water was installed near the base of the tank to prevent the accumulation of water pressure under the ice sheet during its growth. Such pressure could cause microcracking of ice or generate additional loads on the tank.

Specimens with the nominal dimensions of $0.60 \mathrm{~m} \times$ $0.30 \mathrm{~m} \times 0.10 \mathrm{~m}$ were prepared by placing high-density polyethylene molds into the tank before seeding (Fig. 1). The tolerance of the specimen dimensions was $\pm 2 \mathrm{~mm}$ (in all stress calculations below, the measured dimensions of the specimens were used). The molds floated with $2-3 \mathrm{~mm}$ of freeboard. Next, the saline water was chilled to about $-1.5^{\circ} \mathrm{C}$, the cold room temperature was dropped to $\approx$ $-20^{\circ} \mathrm{C}$, and the tank was seeded by spraying a very fine mist of fresh water over the tank as is typically done to seed ice sheets in larger-scale test basins (Gow, 1984; Li and Riska, 1996).

After the seeding, the room temperature was increased to $-14{ }^{\circ} \mathrm{C}$ for $3 \mathrm{~d}$ and then $-10{ }^{\circ} \mathrm{C}$ for $2 \mathrm{~d}$ to produce the desired specimen thickness of $10 \mathrm{~cm}$. The ice sheets made using 24 and $34 \mathrm{ppt}$ saline water reached average salinities of 5 and $7 \mathrm{ppt}$, respectively, and their densities were $886 \pm 19$ and $879 \pm 16 \mathrm{~kg} \mathrm{~m}^{-3}$, respectively.

The specimens used in the dry experiments (Figs. 2a and 3 ) were sealed in plastic bags and stored in a freezer at $-10^{\circ} \mathrm{C}$ for $1-2 \mathrm{~d}$ before testing. However, for the floatingice experiments (see Fig. 2b), the specimens were ejected from the molds, placed in plastic bags with water from the growth tank and quickly transferred to the test basin to minimize brine drainage during the transfer.

Before the experiments, the columnar microstructure of the ice was verified by producing and inspecting thin sections as detailed by Langway (1958). Of special interest was the microstructure close to the specimen boundaries since 


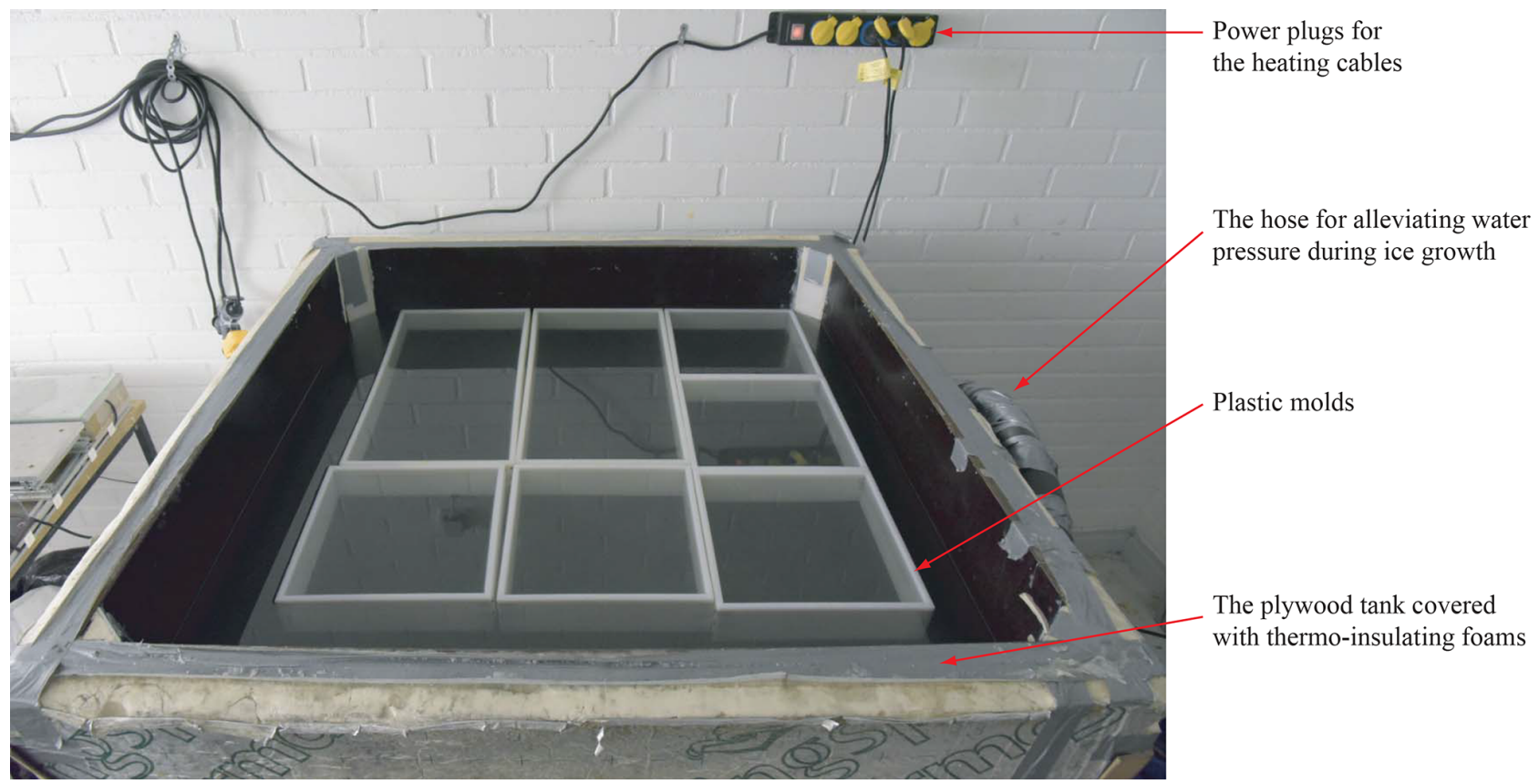

Figure 1. The tank made of plywood for growing ice specimens.

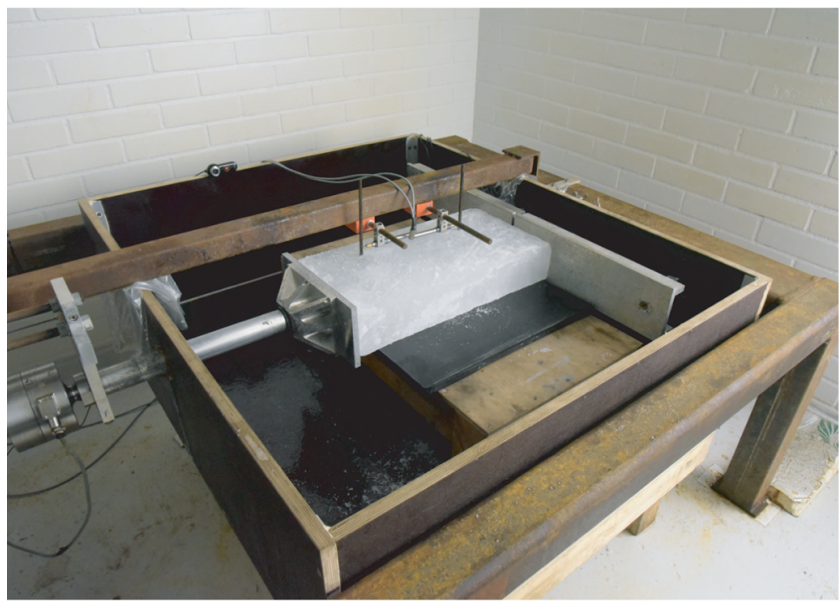

(a)

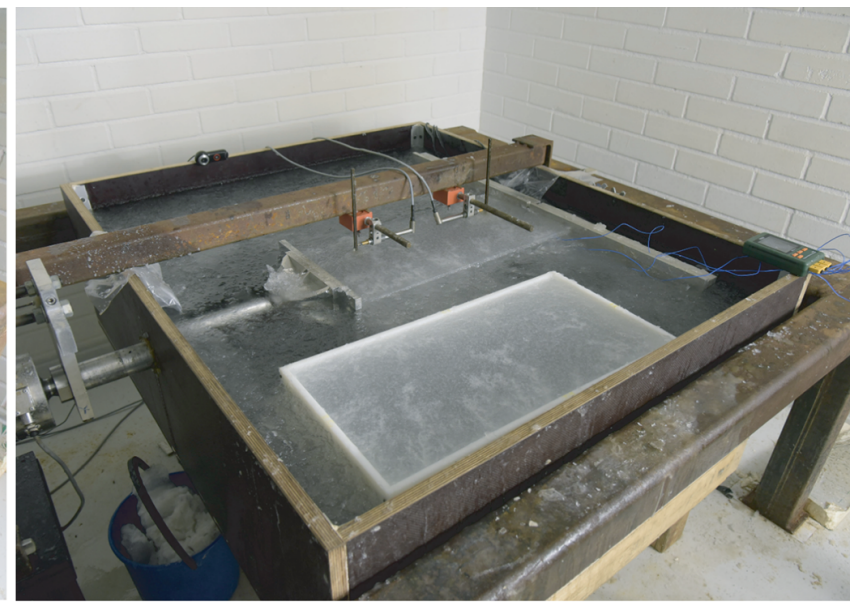

(b)

Figure 2. Equipment used in the (a) dry and (b) floating-ice experiments. One of the plastic molds used when growing ice is shown in (b). The thin ice cover of the basin, seen in (b), was broken before performing the experiments.

such molds are somewhat uncommon in ice specimen preparation. Figure 4 shows two typical thin sections from near the boundary of a specimen produced using $24 \mathrm{ppt}$ saline water; one is for the vertical and the other for the horizontal direction as indicated. Figure 4a shows the columnar structure of the ice. The horizontal view in Fig. $4 \mathrm{~b}$ provides a way to estimate the average grain size by dividing the section area by the number of grains; the average grain size was $\approx 3.5 \mathrm{~mm}$. The Schmidt equal area net pole projection for one of the thin sections shown in Fig. 5 confirms that the $c$ axes were unaligned in the horizontal plane, as intended.

\subsection{Equipment, test matrix and experimental procedure}

The experiments were conducted in the same cold chamber used for the saline-ice production. As Figs. 2 and 3 illustrate, an externally mounted electrohydraulic cylinder applied loads to the specimens. The piston passed through a sealed port in the side of the test tank. The piston had a max- 


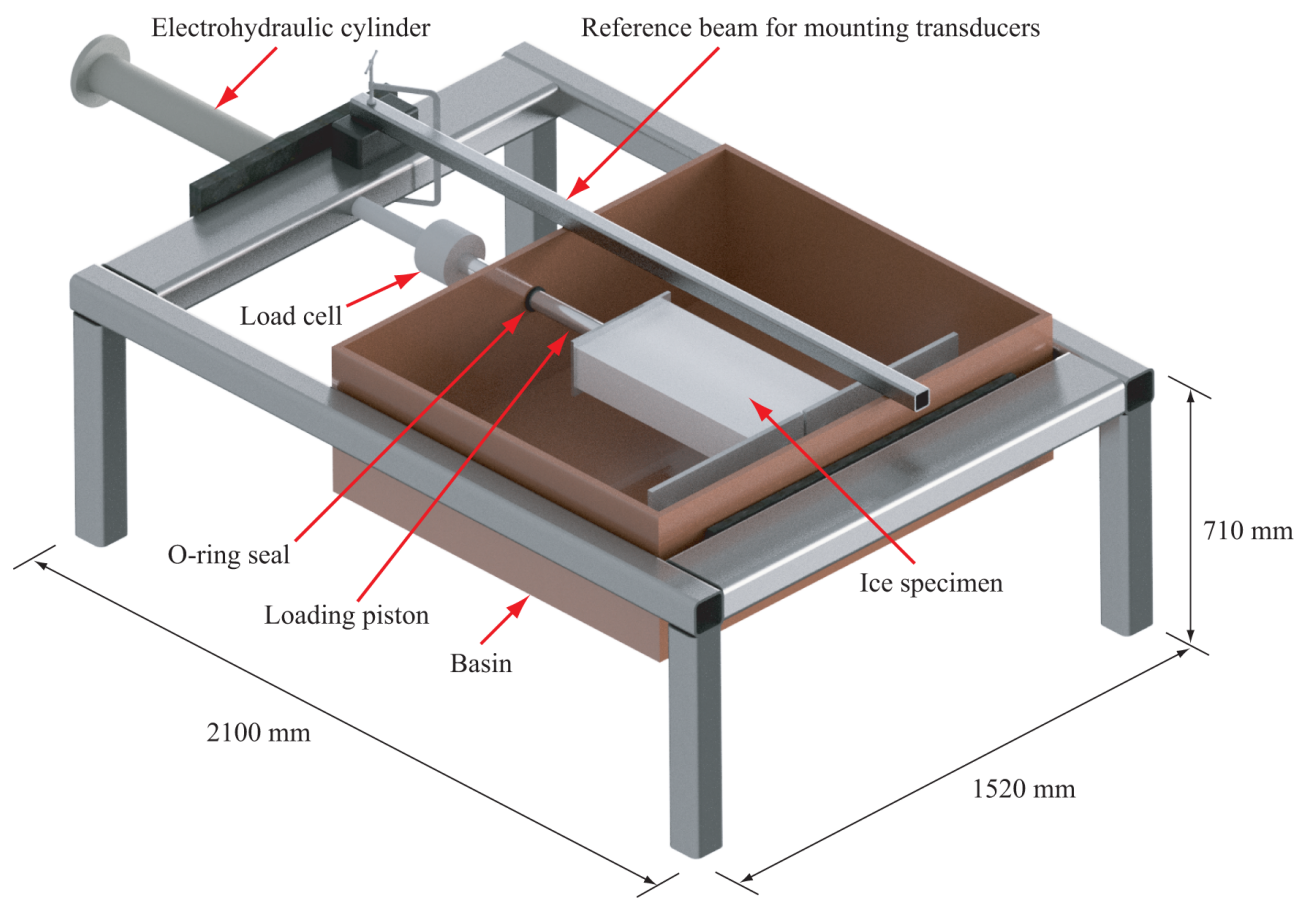

Figure 3. A sketch of the test rig used in the experiments. The inner dimensions of the basin are $1320 \mathrm{~mm} \times 1280 \mathrm{~mm} \times 400 \mathrm{~mm}$.

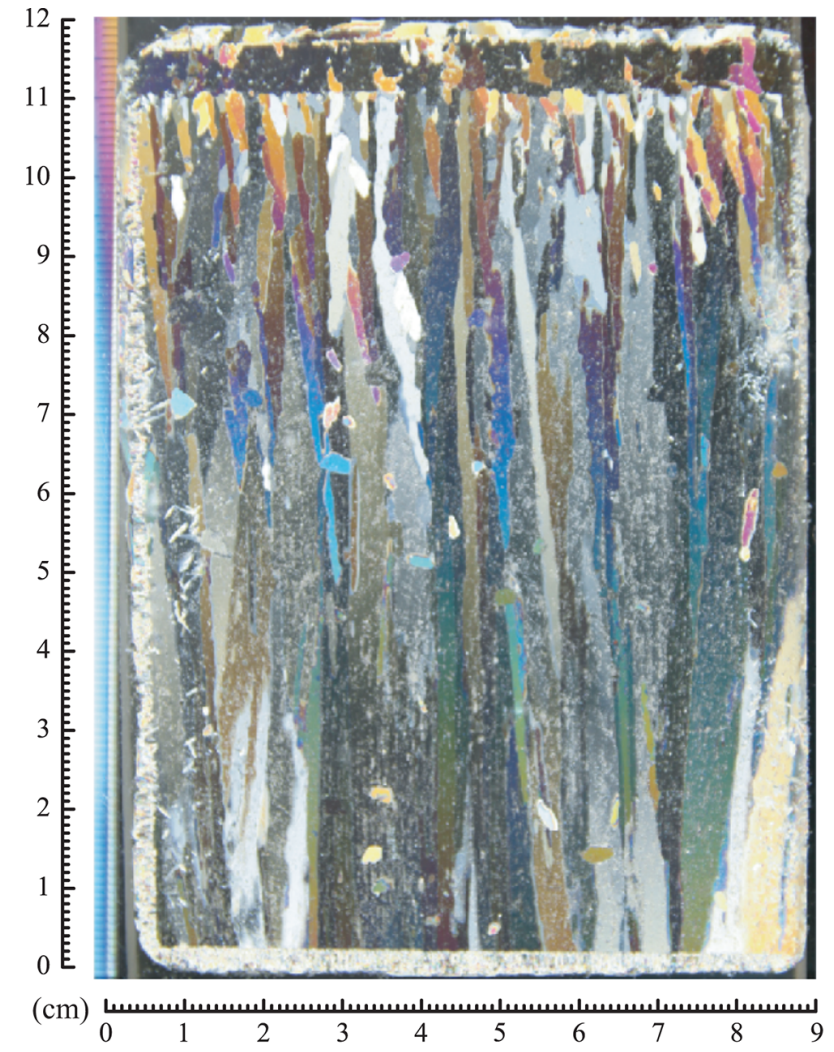

(a)

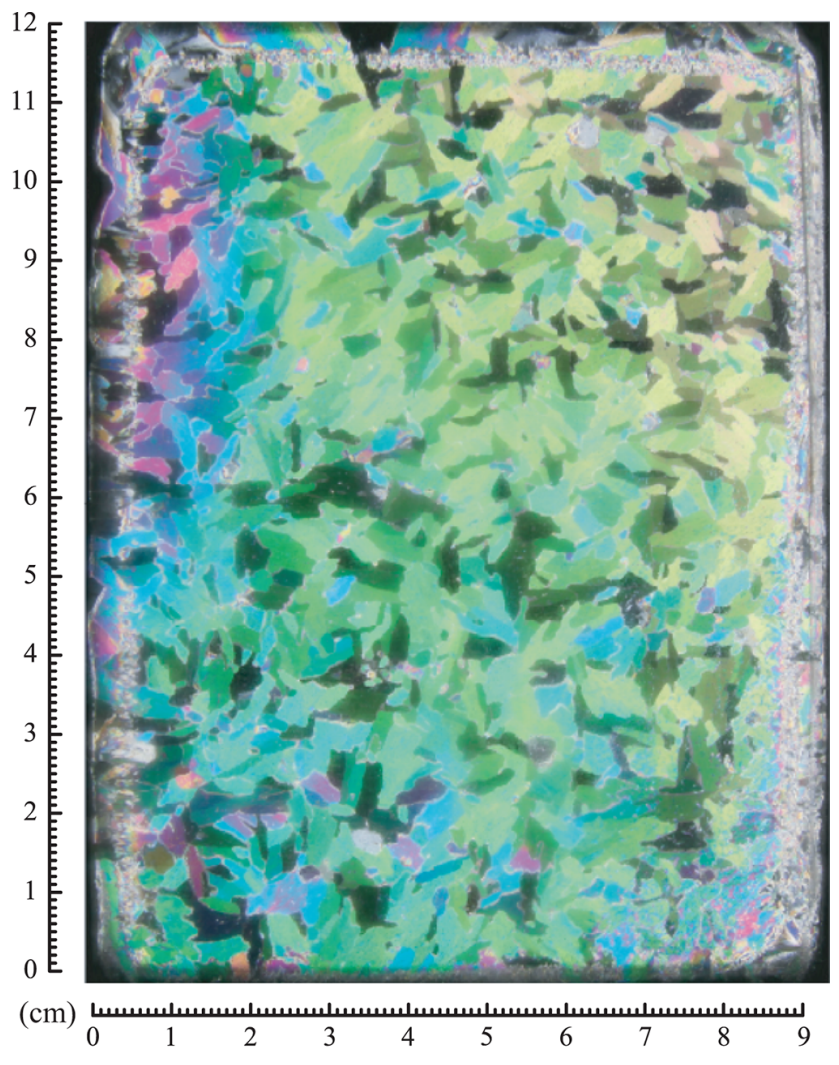

(b)

Figure 4. One set of thin sections of the ice (salinity: $5 \mathrm{ppt)}$ grown in this experimental campaign: (a) vertical, (b) horizontal. 


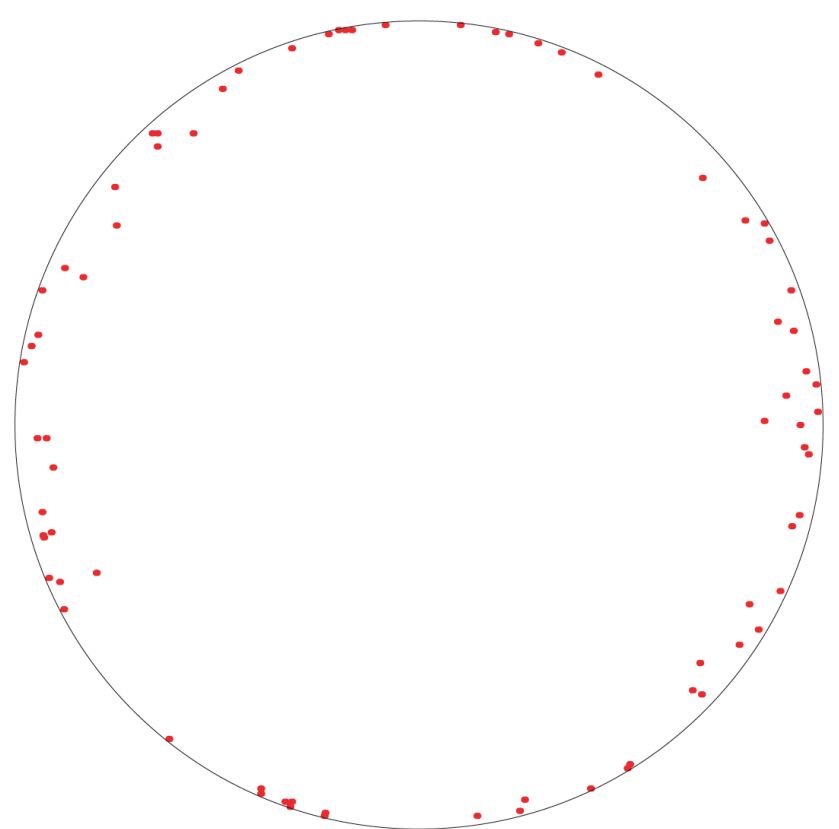

Figure 5. A typical Schmidt equal area net pole projection drawn on the basis of grain orientations.

imum stroke of $800 \mathrm{~mm}$ and a loading capacity of $100 \mathrm{kN}$ for compression and $60 \mathrm{kN}$ for tension. The load cell had an accuracy of $\pm 5 \mathrm{~N}$, which is sufficient for all stress levels and cycles of the experiments here. The test basin was constructed of waterproof plywood. The system employed a camera for remote monitoring of the experiments, a threechannel temperature data logger to record the temperature profile of floating ice during testing, a data acquisition processor (DAP) board (model: Data Translation DT9834) and fixtures for arranging displacement sensors to the ice specimens. The temperature data logger had a maximum sampling rate of one datum per $5 \mathrm{~s}$; its measurement range was from -100 to $1300^{\circ} \mathrm{C}$, and it had an accuracy of $\pm 0.5^{\circ} \mathrm{C}$. The DAP board could achieve a maximum scan rate of 500000 samples per second.

The loading system has a self-equilibrating geometry in that the compressive force applied by the electrohydraulic piston and transmitted through the specimen is balanced by a tensile force in the external load frame (Fig. 3). Care was taken to center the loading piston and the reaction plates on the vertical dimension of the load frame.

The ice deformation was measured as follows. Before the test, two holes were drilled into the specimen. Two iron rods with a cross section of $5 \mathrm{~mm} \times 5 \mathrm{~mm}$ were then inserted into the holes and frozen in place using a small quantity of cold fresh water. The relative displacement of the rods was monitored by two linear variable differential transformer transducers (LVDTs; model: HBM WA2, with a measurement range and accuracy of 2 and $\pm 0.001 \mathrm{~mm}$, respectively). This relative displacement was used to determine the strain response of the specimen. As shown in Figs. 2 and 3, the LVDTs were mounted on a rectangular piece of steel placed across the basin.

The air temperature was kept at $-10^{\circ} \mathrm{C}$ during all testing. To measure the through-thickness temperature gradient in all of the floating-ice experiments, temperature probes were frozen into three $2.5 \mathrm{~mm}$ diameter, $50 \mathrm{~mm}$ deep holes that were drilled on one side face of the specimen. As shown in a sketch in Fig. 6a, one measurement point was in the middle of the specimen from the vertical direction, and the other two were $1.5 \mathrm{~mm}$ away from the upper and lower surfaces of the specimen, respectively. During each floating-ice experiment, temperature readings from all three channels remained constant for the duration of the experiment, indicating that the thermal gradient was unaffected by the cyclic loading.

Figure $6 \mathrm{~b}$ presents typical temperature profiles measured in two floating-ice specimens. For the $5 \mathrm{ppt}$ saline floating ice, the temperature near the top surface, in the middle and near the bottom surface of the specimen was measured to be $-3.0,-2.3$ and $-2.2^{\circ} \mathrm{C}$, respectively, while the values were $-3.1,-2.4$ and $-2.1^{\circ} \mathrm{C}$, respectively, for the $7 \mathrm{ppt}$ saline ice floe. These temperature readings suggest that the average temperature of the floating ice was $-2.5^{\circ} \mathrm{C}$, much higher than the air temperature of the cold chamber $\left(-10^{\circ} \mathrm{C}\right)$. The water temperature at $5 \mathrm{~cm}$ below the water surface was measured to be $\approx-1.8^{\circ} \mathrm{C}$ in the floating-ice tests.

The test matrix called for applying relatively low cyclic compressive stress levels with the system in load control. Figure 7 presents the loading waveforms used in the experiments, and the test matrix is given in Table 1 . In the experiments, the ice was first loaded with a linear ramp to reach an initial compressive stress level, at which point a compressive haversine waveform was immediately applied. In Fig. $7 \mathrm{a}, \sigma_{\max }$ and $\sigma_{\min }$ represent the upper and the lower bounds of the cyclic compressive stress, respectively, and $T$ denotes the period for one loading cycle. As indicated by Table 1 , six periods ranging from 1 to $10^{3} \mathrm{~s}$ were employed; these periods cover the main range of ocean wave periods, which usually vary from several seconds to tens of seconds (Reistad et al., 2011; Zijlema et al., 2012). In each dry test, only a fixed frequency was applied. Once the test was completed, the specimen recovered for $15 \mathrm{~min}$ before subsequent load cycles were applied. For all dry tests, the duration of the initial loading ramp was fixed to be $1 \mathrm{~s}$. In each of the tests corresponding to $T=1,5,10$ and $100 \mathrm{~s}, 18$ cycles were applied $(N=18)$, while for those with $T=500$ and $1000 \mathrm{~s}, N$ equaled 9 and 4 , respectively. The sequence of loading cycles was in ascending order of $T$ in all cases. As a time-saving measure and to avoid freezing of the open water in the basin, cyclic stresses with increasing periods were applied continuously in the floating-ice tests. The number of cycles for each period was as follows: for $T=1,5$ or $10 \mathrm{~s}, N$ equals 10 ; for $T=100 \mathrm{~s}, N$ equals 2 ; and for $T=500$ or $1000 \mathrm{~s}, N$ equals 1. 


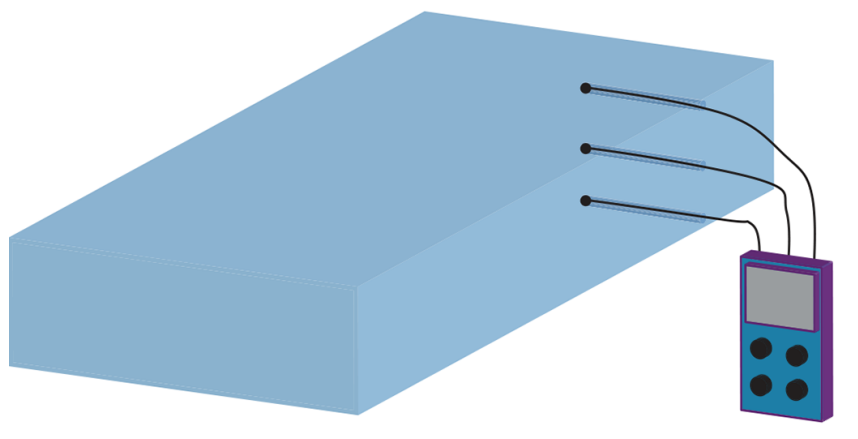

Floating ice sample Temperature data logger

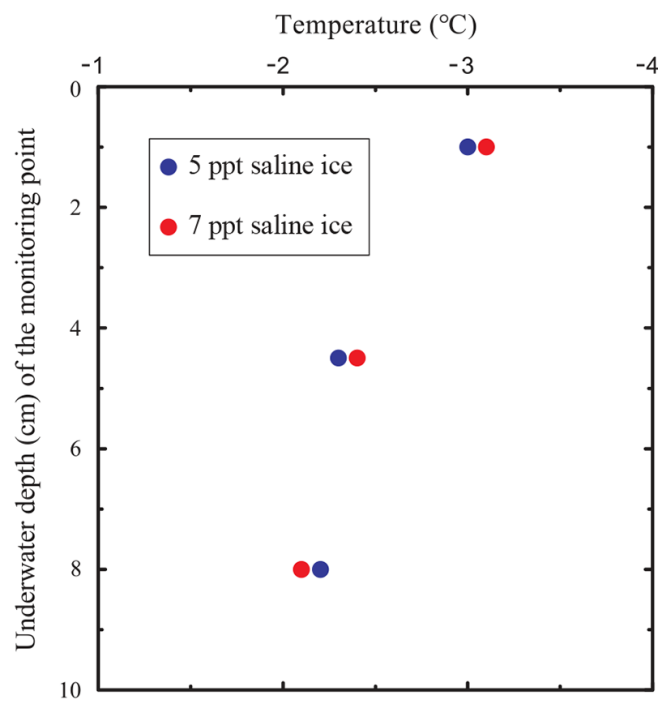

(b)

(a)

Figure 6. Monitoring of the through-thickness thermal gradient of floating ice: (a) a schematic diagram of the arrangement of the temperature probes and (b) the measured through-thickness thermal gradient inside two floating-ice specimens.

Table 1. The test matrix of this experimental campaign. The campaign included two test types, two ice salinities, six periods and two test-type-dependent load levels. For each case, two specimens harvested from two ice sheets were tested.

\begin{tabular}{llrlrlr}
\hline Case & $\begin{array}{l}\text { Specimen } \\
\text { no. }\end{array}$ & $\begin{array}{r}\text { Ice salinity } \\
(\mathrm{ppt})\end{array}$ & $\begin{array}{l}\text { Dry/ } \\
\text { floating }\end{array}$ & $\begin{array}{r}\text { Average ice } \\
\text { temperature }\left({ }^{\circ} \mathrm{C}\right)\end{array}$ & $\begin{array}{l}\text { Period } \\
(\mathrm{s})\end{array}$ & $\begin{array}{r}\text { Cyclic compressive } \\
\text { stresses }(\mathrm{MPa})\end{array}$ \\
\hline I & Dry-5ppt-1, Dry-5ppt-2 & 5 & Dry & -10 & $1,5,10,100,500,1000$ & $0.08-0.25$ \\
II & Dry-7pt-1, Dry-7ppt-2 & Dry & -10 & $1,5,10,100,500,1000$ & $0.08-0.25$ \\
III & Floating-5ppt-1, Floating-5ppt-2 & 5 & Floating & -2.5 & $1,5,10,100,500,1000$ & $0.04-0.12$ \\
IV & Floating-7ppt-1, Floating-7ppt-2 & 7 & Floating & -2.5 & $1,5,10,100,500,1000$ & $0.04-0.12$ \\
\hline
\end{tabular}

The cyclic compressive stress applied to the dry specimens varied from 0.08 to $0.25 \mathrm{MPa}$, which could be justifiably expected to not lead to severe damage of the specimen while being high enough to generate measurable strain (Cole and Dempsey, 2001). The stress in the floating experiments was lower, varying from 0.04 to $0.12 \mathrm{MPa}$, to avoid damage. For each case listed in Table 1, two specimens harvested from two ice sheets were subjected to each set of conditions. The specimens were named according to their salinity, test conditions (dry/floating), and the ice sheet from which they originated. For example, specimen name Dry-5ppt-1 indicates that it came from the first 5 ppt saline ice sheet and was tested under dry, isothermal conditions.

Figure $7 \mathrm{~b}$ illustrates how the energy dissipation in the cyclic loading experiments was calculated. For common engineering materials subjected to uniaxial cyclic compression, the strain along the compressive direction versus the stress is usually characterized by hysteresis loops. The strain energy density dissipated in a loading cycle can be determined by integrating the stress-strain curve. As shown in Fig. 7b, the area under the loading curve (region $\mathrm{ABCF}$ ) represents the maximum strain energy input via the testing machine during a load cycle, and the area under region CDEF denotes the strain energy released during the unloading portion of the cycle. The energy density dissipation (EDD) in one full loading-unloading cycle is given by the difference between the areas of regions ABCF and CDEF (Liu et al., 2017, 2018). The energy density consumed in the hysteresis loop can, in general, be attributed to the internal friction and, in some cases, damage to the material. For each cycle, the energy dissipation rate (EDR) can be defined as the ratio of the dissipated energy to the input energy, namely the area of the region $\mathrm{ABCDE}$ divided by that of the region $\mathrm{ABCF}$.

\section{Experimental results}

Figure 8 presents strain-time plots obtained from the dry experiments using specimen Dry-5ppt-1 under the indicated conditions. The strain-time curves manifest the following feature: if a line were drawn through the maximum value for each cycle, the slope of the line would first decrease from 


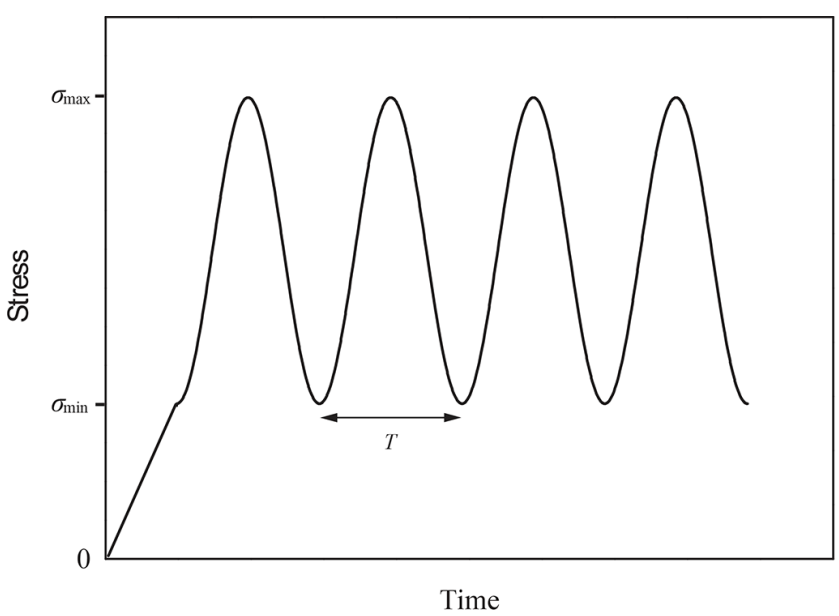

(a)

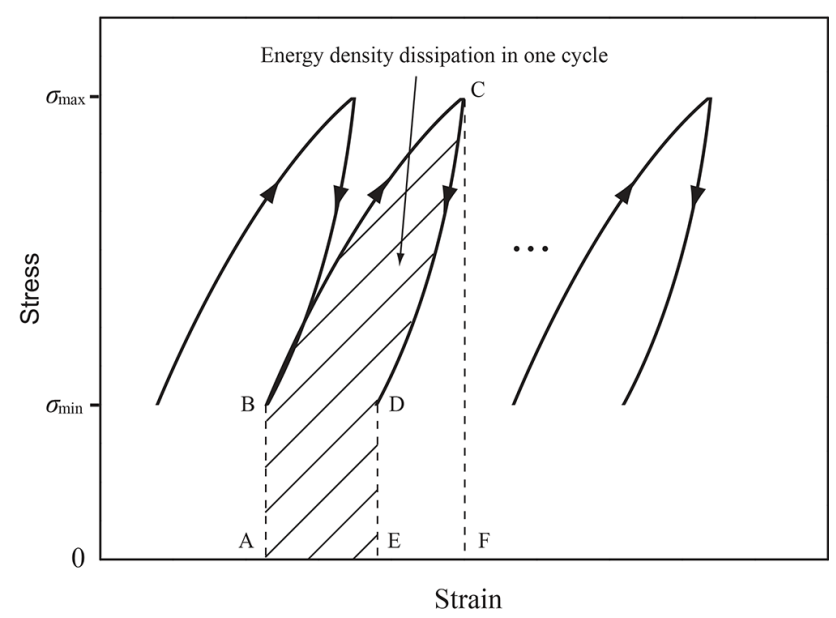

(b)

Figure 7. Schematic diagrams of the cyclic loads: (a) the inputted stress waveform and (b) the method for calculating the energy density dissipated in one loading cycle (in other words, region ABCDE).
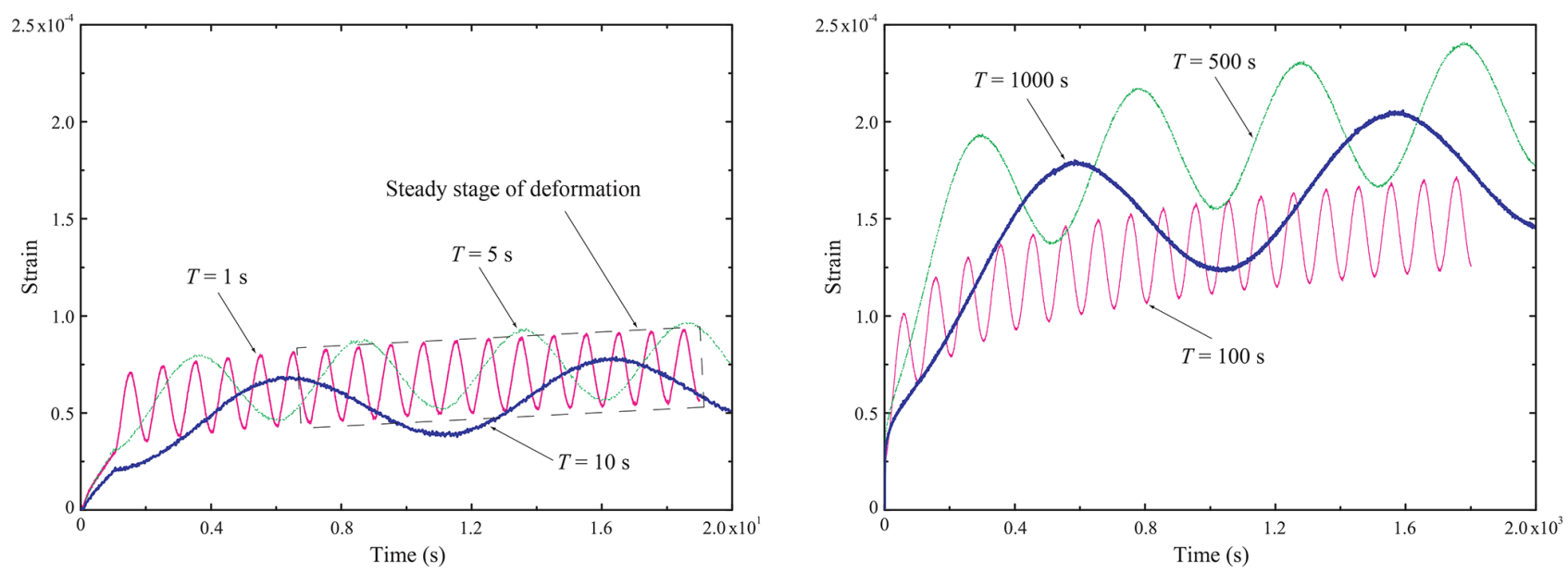

Figure 8. Strain-time curves of specimen Dry-5ppt-1 tested with stresses varying from 0.08 to $0.25 \mathrm{MPa}$ and with a temperature of $-10{ }^{\circ} \mathrm{C}$.

its initial value for some number of cycles and then settle down to an almost-constant value. This observation means that the strain response of the ice specimen under sinusoidal compressive stress reaches a relatively steady stage after the initial transient of the anelastic strain is exhausted and that in this steady stage the accumulated viscous or permanent strain increases linearly with time. In addition, Fig. 8 shows that the longer the period $T$ of cyclic loading, the larger the strain amplitude in one steady-stage cycle. The total amount of strain does not strictly increase with the loading period. This may be because the loading platen and the specimen did not always achieve perfect contact immediately, causing some error in the strain measured in this initial stage of loading. Once intimate contact was achieved, the measured strain became reliable.
Figure 9 shows the stress-strain curves for the same experiments. In each case, the area of the hysteresis loop for the first few cycles was comparatively large and then gradually decreased to a constant value as the specimen reached the steady deformation stage described in the previous paragraph. For example, the hysteresis loops after the first stress cycle in the dry experiment with $T=1000 \mathrm{~s}$ are similar; $N=4$ is enough for the dry specimen at $T=1000 \mathrm{~s}$ to show steady-state response. Thus, the EDD (Fig. 7b) decreases from its initial value to an approximately constant value. It is clear that the steady-state hysteresis loop area increases with the period of the cyclic loading, consistent with earlier studies (Cole, 1990; Murdza et al., 2018; Weber and Nixon, 1996).

Figures 10 and 11 display a set of strain-time plots and the corresponding stress-strain curves for the floating-ice exper- 

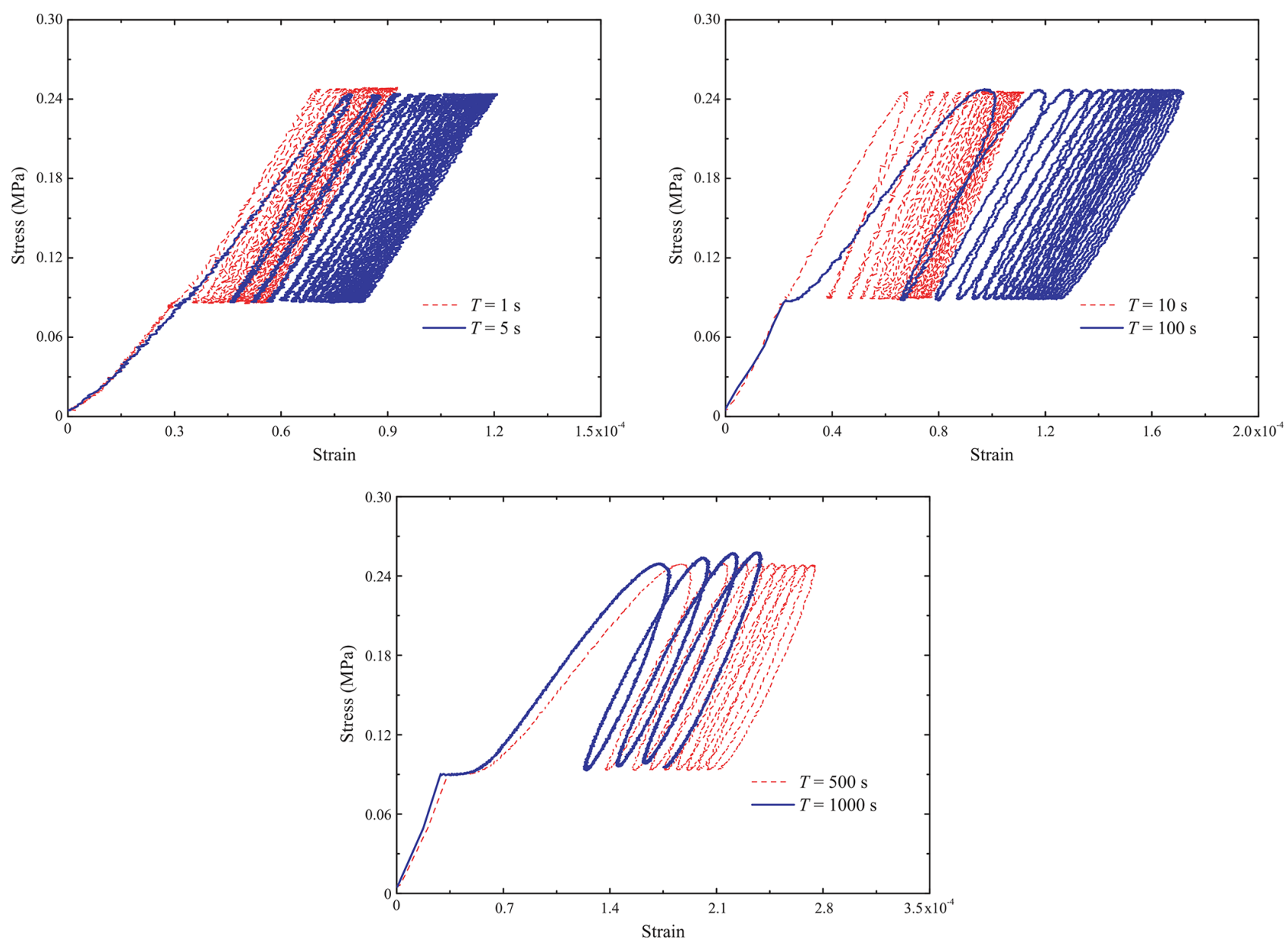

Figure 9. Stress-strain curves of specimen Dry-5ppt-1 tested with stresses varying from 0.08 to $0.25 \mathrm{MPa}$ and with a temperature of $-10{ }^{\circ} \mathrm{C}$.

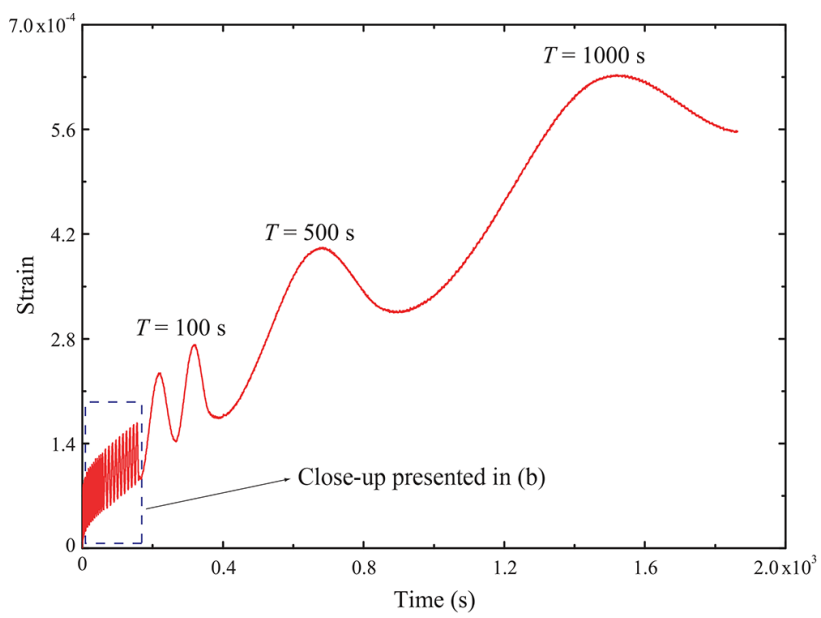

(a)

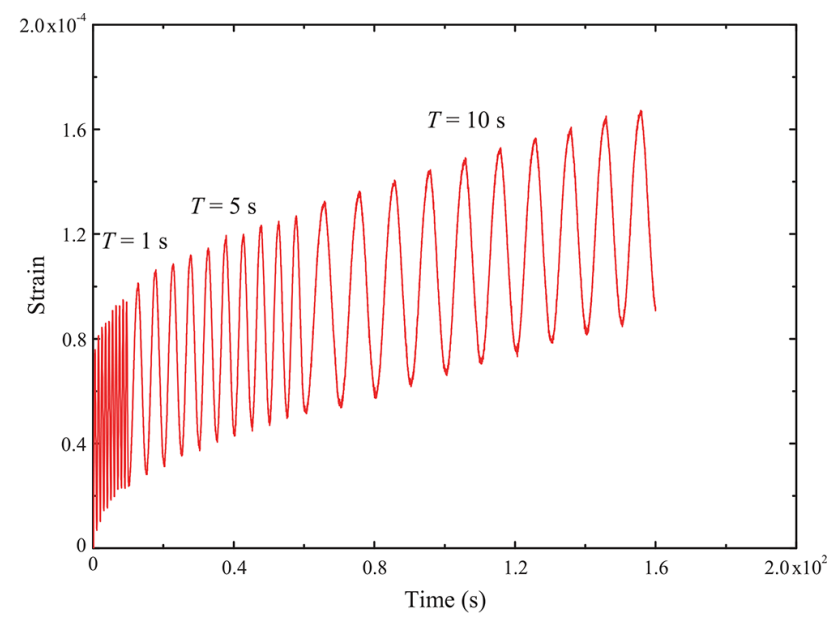

(b)

Figure 10. Strain response of specimen Floating-5ppt-1 tested with stresses varying from 0.04 to $0.12 \mathrm{MPa}$ and with an average temperature of $-2.5^{\circ} \mathrm{C}$ : (a) shows the response for all periods, $T$, of cyclic loading, while (b) presents a close-up showing the cycles for $T=1,5$ and $10 \mathrm{~s}$. 


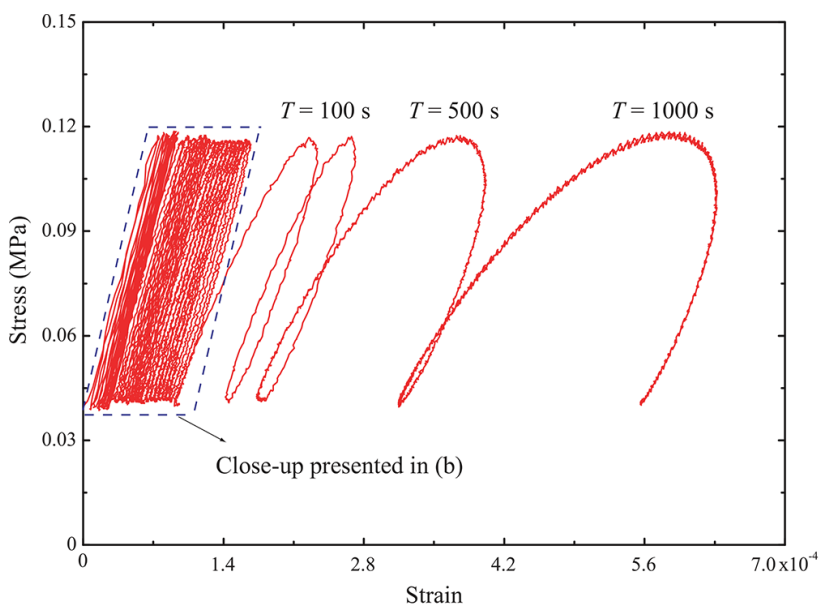

(a)

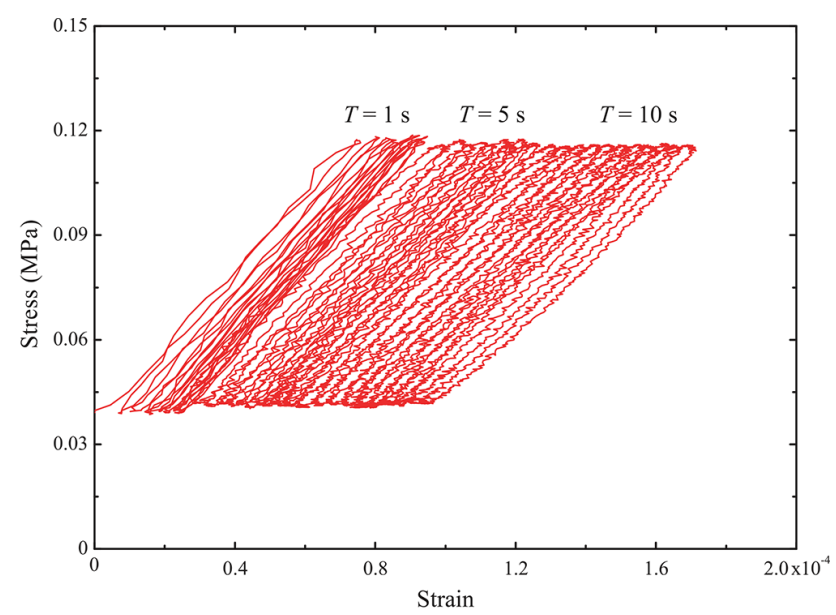

(b)

Figure 11. Stress-strain plots of specimen Floating-5ppt- 1 tested with stresses varying from 0.04 to $0.12 \mathrm{MPa}$ and with an average temperature of $-2.5^{\circ} \mathrm{C}$ : (a) shows the response for all periods, $T$, of cyclic loading, while (b) presents a close-up showing the cycles for $T=1,5$ and $10 \mathrm{~s}$.

Table 2. The energy density $\left(\mathrm{J} \mathrm{m}^{-3}\right)$ dissipated in a typical loadingunloading cycle of each experiment.

\begin{tabular}{lrrrrr}
\hline Specimen no. & \multicolumn{5}{c}{ Frequency (Hz) } \\
\cline { 2 - 6 } & 0.001 & 0.002 & 0.01 & 0.1 & 0.2 \\
\hline Dry-5ppt-1 & 8.83 & 5.44 & 2.01 & 0.67 & 0.71 \\
Dry-5ppt-2 & 5.36 & 2.93 & 1.57 & 0.54 & 0.36 \\
Dry-7ppt-1 & 14.4 & 7.16 & 2.87 & 0.91 & 0.66 \\
Dry-7ppt-2 & 20.8 & 14.0 & 7.80 & 2.49 & 2.05 \\
Floating-5ppt-1 & 25.0 & 15.4 & 4.78 & 0.85 & 0.63 \\
Floating-5ppt-2 & 28.4 & 16.2 & 4.79 & 0.91 & 0.54 \\
Floating-7ppt-1 & 151 & 67.7 & 20.2 & 3.85 & 2.52 \\
Floating-7ppt-2 & 63.6 & 38.3 & 11.7 & 2.40 & 1.63 \\
\hline
\end{tabular}

iments on the $5 \mathrm{ppt}$ saline ice specimens, respectively. The curves in these two figures show similar features to those in Figs. 8 and 9 for dry experiments. The floating ice also reached a steady state of deformation after some loading cycles, and the amplitude of the steady-state strain response still increased with $T$. Similar to the results of the dry experiments, Fig. 11 indicates that the longer the loading period, the larger the strain increment of the floating specimen under one steady-state loading-unloading cycle. Comparison of Figs. 9 and 11 in the steady state shows that, for constant $T$, both the strain increment per cycle and the area of one hysteresis loop, are larger in the floating-ice experiments than in the dry experiments even though the stress levels are lower than in the dry experiments. It is thus evident that the decreased stress levels in the floating-ice experiments did not fully compensate for the temperature effects on the viscous and viscoelastic components of strain as, for example, the
Table 3. The energy dissipation rate (\%) in a typical loadingunloading cycle of each experiment.

\begin{tabular}{lrrrrr}
\hline Specimen no. & \multicolumn{5}{c}{ Frequency (Hz) } \\
\cline { 2 - 6 } & 0.001 & 0.002 & 0.01 & 0.1 & 0.2 \\
\hline Dry-5ppt-1 & 48.3 & 40.2 & 22.0 & 9.86 & 9.93 \\
Dry-5ppt-2 & 35.4 & 22.7 & 17.6 & 8.68 & 5.50 \\
Dry-7ppt-1 & 55.6 & 37.3 & 21.6 & 11.0 & 8.60 \\
Dry-7ppt-2 & 55.7 & 44.7 & 32.3 & 16.0 & 14.3 \\
Floating-5ppt-1 & 89.6 & 76.1 & 44.2 & 15.5 & 11.8 \\
Floating-5ppt-2 & 87.7 & 69.8 & 39.4 & 17.4 & 11.3 \\
Floating-7ppt-1 & 98.3 & 91.7 & 70.5 & 32.0 & 25.1 \\
Floating-7ppt-2 & 88.1 & 76.0 & 56.4 & 26.3 & 20.2 \\
\hline
\end{tabular}

viscous strain rate of a floating $5 \mathrm{ppt}$ saline ice specimen is 14 times that of the corresponding dry specimen.

The energy density dissipation (EDD) and the energy dissipation rate (EDR) per cycle during steady-stage deformation (Sect. 2.2 and Fig. 7b) allow quantitative comparisons of the inelastic behavior of specimens as a function of test conditions. These are presented in Tables 2 and 3 for all experiments except the $1 \mathrm{~s}$ period experiment, for which the hysteresis loop areas are too small for accurate measurements. Tables 2 and 3 indicate that both the EDD and the EDR decrease with the increase in loading frequency. Moreover, under the same frequency, the $7 \mathrm{ppt}$ saline ice has larger EDD and EDR values than the $5 \mathrm{ppt}$ saline ice irrespective of the experiment type. In addition, the floating-ice experiments always exhibit higher EDD and EDR values than the dry experiments regardless of the ice salinities. The differences in the values of EDD are especially significant for low frequencies. For example, in the experiments with $T=1000 \mathrm{~s}$, the 
average value of EDD for the 5 ppt saline dry specimens is only $24 \%$ of that of the 5 ppt saline floating specimens and $44 \%$ of that of the $7 \mathrm{ppt}$ saline dry specimens. However, for the experiments with $T=5 \mathrm{~s}$, the average value of EDD in the former case is $47 \%$ and $77 \%$ of that in the latter two cases, respectively. Thus, the ice salinity and the test conditions have a more significant influence on the energy dissipation of the ice when the cyclic loading period is long.

\section{Material modeling}

The hysteresis loops of the stress-strain curves manifest viscous and anelastic properties of the ice. According to previous studies (Cole, 1995; Leclair et al., 1999), in low-stress cyclic loading experiments, the microstructure of the ice remains unaffected by loading, or in other words, no damage occurs within the material. In the present case of polycrystalline ice, the anelastic deformation is mainly attributed to two relaxation mechanisms: lattice dislocation relaxation and grain boundary sliding. Viscous straining is attributable to basal dislocation. In this section, a dislocation-based model (Cole, 1995; Cole and Durell, 2001), which accounts for these mechanisms, is used to predict the strain response of the ice specimens based on their physical properties and experimental conditions. Here the model is only briefly described, but a detailed description can be found from Cole et al. (1998), where the model is also demonstrated to reproduce the viscous and anelastic behavior of dry specimens. Here the applicability of the model in predicting the behavior of floating laboratory-prepared ice specimens subjected to cyclic loading is tested for the first time.

\subsection{Brief description of the model}

In the physically based model by Cole (1995) and Cole and Durell (2001), the axial strain, $\varepsilon$, of ice under uniaxial cyclic compression is considered to be composed of elastic, anelastic (delayed elastic) and viscous components, denoted here as $\varepsilon_{\mathrm{e}}, \varepsilon_{\mathrm{a}}$ and $\varepsilon_{\mathrm{v}}$, respectively. The axial strain is expressed as

$\varepsilon=\varepsilon_{\mathrm{e}}+\varepsilon_{\mathrm{a}}+\varepsilon_{\mathrm{v}}$.

In the case of sinusoidal stress waveform, $\varepsilon_{\mathrm{e}}$ can be written as

$\varepsilon_{\mathrm{e}}=\frac{\sigma(\omega, t)}{E_{0}}$,

where $\omega$ is the angular frequency of the stress waveform, and $E_{0}$ is the unrelaxed modulus. Although detailed expressions have been developed for the effective elastic modulus as a function of crystallography, brine and gas porosity, and temperature, a simplified approach is adopted in the present effort. The anelastic component $\varepsilon_{\mathrm{a}}$ incorporates both above-mentioned relaxation mechanisms to represent the time-dependent recoverable deformation. For the steadystage deformation, $\varepsilon_{\mathrm{a}}$ of ice subjected to sinusoidal compressive stress can be decomposed as (Cole and Dempsey, 2001)

$\varepsilon_{\mathrm{a}}=\sigma(\omega, t)\left[D_{1}^{\mathrm{d}}(\omega)+D_{2}^{\mathrm{d}}(\omega)+D_{1}^{\mathrm{gb}}(\omega)+D_{2}^{\mathrm{gb}}(\omega)\right]$,

where the compliance terms, $D$, with the superscripts "d" and "gb" denote the compliances induced by dislocation and grain boundary sliding, respectively. The compliance terms are defined as (Cole et al., 1998)

$$
\begin{aligned}
& D_{1}^{\mathrm{d}}(\omega)=\delta D^{\mathrm{d}}\left\{1-\frac{2}{\pi} \tan ^{-1}\left[e^{\left(\alpha^{\mathrm{d}} s^{\mathrm{d}}\right)}\right]\right\} \\
& D_{1}^{\mathrm{gb}}(\omega)=\delta D^{\mathrm{gb}}\left\{1-\frac{2}{\pi} \tan ^{-1}\left[e^{\left(\alpha^{\mathrm{gb}} s^{\mathrm{gb} b}\right.}\right]\right\} \\
& D_{2}^{\mathrm{d}}(\omega)=\alpha^{\mathrm{d}} \cdot \delta D^{\mathrm{d}} \frac{1}{e^{\left(\alpha^{\mathrm{d}} s^{\mathrm{d}}\right)}+e^{\left(-\alpha^{\mathrm{d}} s^{\mathrm{d}}\right)}} \\
& D_{2}^{\mathrm{gb}}(\omega)=\alpha^{\mathrm{gb}} \cdot \delta D^{\mathrm{gb}} \frac{1}{e^{\left(\alpha^{\mathrm{gb}} s^{\mathrm{gb}}\right)}+e^{\left(-\alpha^{\mathrm{gb}} s^{\mathrm{gb}}\right)}},
\end{aligned}
$$

where $S^{\mathrm{d}}=\ln \left(\tau^{\mathrm{d}} \omega\right) ; \tau^{\mathrm{d}}$ is the central relaxation time (Cole and Durell, 1995). The term $\alpha$ is a so-called peak-broadening term, which accounts for the effect of a distribution in relaxation times of the basal-plane dislocations. The grain boundary relaxation is calculated using similar mathematic expressions as the dislocation relaxation but has a different strength, activation energy and peak-broadening term. The activation energy is $1.32 \mathrm{eV}$ for the grain boundary relaxation and $0.55 \mathrm{eV}$ for the dislocation relaxation (Cole and Dempsey, 2001). The peak-broadening terms for lattice dislocation relaxation and grain boundary sliding relaxation are typically $\approx 0.5$ and 0.6 , respectively, determined experimentally by Cole (1995) and Cole and Dempsey (2001) and also validated by Heijkoop et al. (2018). The strength of the dislocation relaxation is calculated from

$\delta D^{\mathrm{d}}=\frac{\rho \Omega b^{2}}{K}$,

where $b$ represents the magnitude of Burgers vector $(b=$ $\left.4.52 \times 10^{-10} \mathrm{~m}\right) ; \rho$ denotes the mobile dislocation density, often found to be on the order of $10^{9} \mathrm{~m}^{-2} ; \Omega$ is an orientation factor, determining the average basal-plane shear stress induced by the background normal stress $(\Omega=1 / \pi \approx 0.32$ for a horizontal specimen made of unaligned columnar ice; Cole, 1995); $K$ is a restoring stress constant, determined as $0.07 \mathrm{kPa}$ for polycrystalline ice in experiments (Cole and Durell, 2001). 
In Eq. (1), the viscous strain $\varepsilon_{\mathrm{V}}$ is often estimated with the following formulae (Cole and Durell, 2001):

$\varepsilon_{\mathrm{V}}=\int_{0}^{t} \dot{\varepsilon}_{\mathrm{V}} d \bar{t}$

$\dot{\varepsilon}_{\mathrm{v}}=\frac{\beta \rho \Omega^{1.5} b^{2} \sigma_{\text {creep }}}{B_{0}} e^{\left(-\frac{Q_{\text {glide }}}{k T^{*}}\right)}$,

where $\beta$ equals $0.3, Q_{\text {glide }}$ equals $0.55 \mathrm{eV}$, and $B_{0}$ equals $1.205 \times 10^{-9} \mathrm{Pas}$. The term $k$ is Boltzmann's constant; $T^{*}$ is the temperature in kelvin. By using the above definitions and equations, the strain of the ice specimen can be finally determined via Eq. (1).

\subsection{Modeling}

In this study, the key quantity to be determined from the experiments is the dislocation density $(\rho)$. With knowledge of the microstructure and orientation factor $(\Omega)$ and given the experimental conditions, the anelastic term $\delta D^{\mathrm{d}}$ and the viscous strain rate can be calculated directly. We opt here to determine $E_{0}$ empirically. This was done by trial and error until the stress-strain curves generated by the model matched with those measured in the experiments with $T=10,100$ and $500 \mathrm{~s}$. By making the slopes of the modeled and experimental hysteresis loops for $T=10 \mathrm{~s}$ comparable, $E_{0}$ could be determined. This is because the behavior of the specimens is mainly dominated by the unrelaxed modulus $E_{0}$ when the loading frequency is high (here 0.1 to $1 \mathrm{~Hz}$ ), as indicated in Figs. 9 and 11. From Eqs. (9) and (10), one can find that the strain increment under one loading cycle is dependent on the dislocation density $\rho$; based on this, the dislocation density $\rho$ was estimated by using the experimental results of $T=100$ and $500 \mathrm{~s}$, and $\delta D^{\mathrm{d}}$ was then determined from Eq. (8). $\delta D^{\mathrm{gb}}$ was determined by referring to previous work (Cole, 1995) because the grain boundary relaxation strength could be reasonably assumed constant for the ice material of interest here, and its effect on inelastic behavior of ice was significantly less than the dislocation mechanism. The values determined for the parameters are tabulated in Table 4. Subsequently, the model based on these parameter values was applied to predict the test results for other loading periods. An example of the comparison of experimental and modeling results is presented in Fig. 12, in which the steady-state strain curves from all dry experiments on the $5 \mathrm{ppt}$ saline ice specimen are accompanied by the simulated ones.

Figure 12 shows that the modeled strain records compare well with those from the experiments with period $T=1,5$ and $1000 \mathrm{~s}$. The model reproduced the steady-state strain response of the specimens very well for all tested frequencies. Figure 13 presents the stress-strain hysteresis loops from the same experiments together with those produced by the model. The hysteresis loops generated by using the model are very similar to those from the experiments. The loop area increases with $T$ in both the experiments and simulations.

For assessing the model in more detail, the values of EDD and EDR derived using it are given in Tables 5 and 6 , respectively, and moreover compared with the data from all the experiments (the test matrix is given in Table 1). Tables 5 and 6 indicate that the model predicts the values of EDD and EDR well for all cyclic loading periods studied here. In general, the error in the predicted EDD and EDR values is within $20 \%$, with the exception of only few cases. No obvious trend between the magnitude of error and loading period or experiment type was observed. Note that for a given ice specimen, one dislocation density value adequately models the steadystate strain responses and energy dissipation values in tests conducted with different frequencies. The value of dislocation density thus remained constant through the cyclic loading.

\subsection{Further validation}

The above results show that the model can yield satisfactory predictions of the viscous and anelastic behavior of both dry and floating specimens. One may argue that the good agreement between the model predictions and the experimental results only indicates the capability of the model to predict the results for the experiments with the same stress levels as those used to calibrate the model parameters. To check whether the model can predict the results of the experiments with different stress levels than those above, additional experiments were performed on specimen Dry-5ppt-1 with higher stress $(0.1-0.3 \mathrm{MPa})$ and on specimen Floating7 ppt-1 with lower stress $(0.005-0.085 \mathrm{MPa}$; nominal cyclic stress of $0.005-0.085 \mathrm{MPa}$ is low, but the setup could achieve it: with the accuracy of the system, the actual stress applied to the specimen was $0.005( \pm 0.001)-0.085( \pm 0.003) \mathrm{MPa})$. The model was then used to determine the strain response and energy dissipation in these tests using the parameterization based on the experiments of Sect. 3 (Table 4).

Figure 14 compares the stress-strain hysteresis loops obtained in the supplementary experiments with the predictions yielded from the model. Good agreement is observed between the predicted and measured hysteresis loops. Again, the relative errors in the EDD and EDR values are found to be less than $20 \%$ for most data sets. The model is, indeed, capable of predicting the deformation of saline ice in a dry environment or when floating in water irrespective of the stress level (given that the stress levels are moderate and do not cause an increase in dislocation density during deformation). The applicability of the model is highlighted by the fact that once the model parameters are calibrated through benchmark experiments (the elastic modulus and dislocation density in the present case), it yields sound predictions for the experiments conducted with other stress levels. 


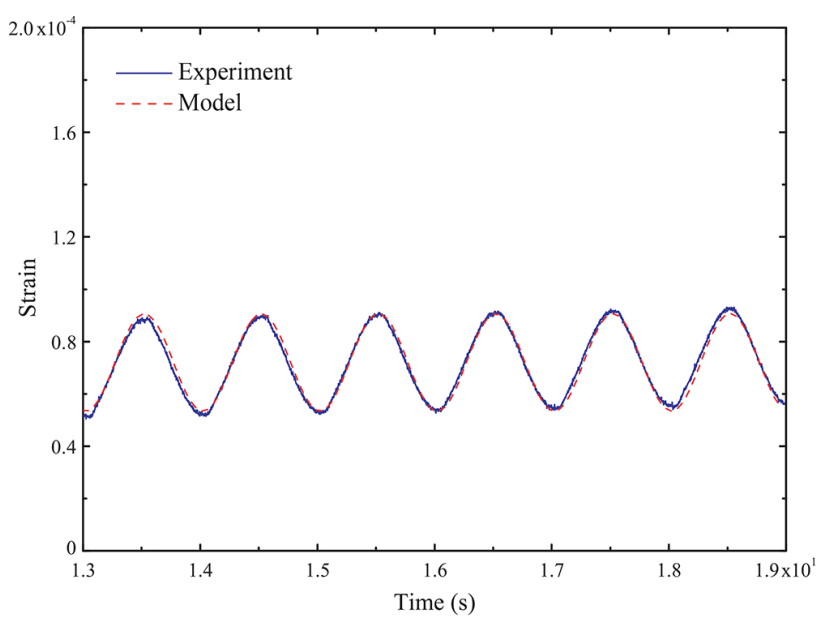

(a) $T=1 \mathrm{~s}$

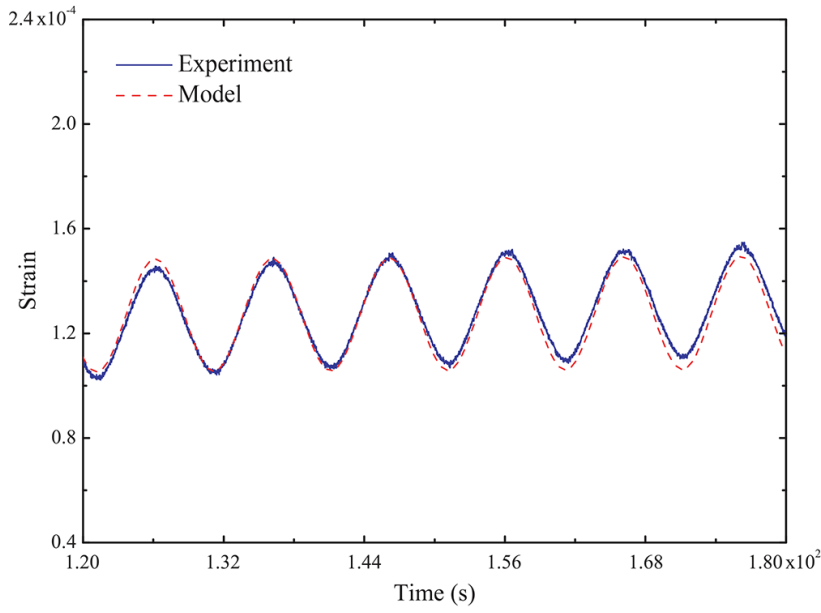

(c) $T=10 \mathrm{~s}$

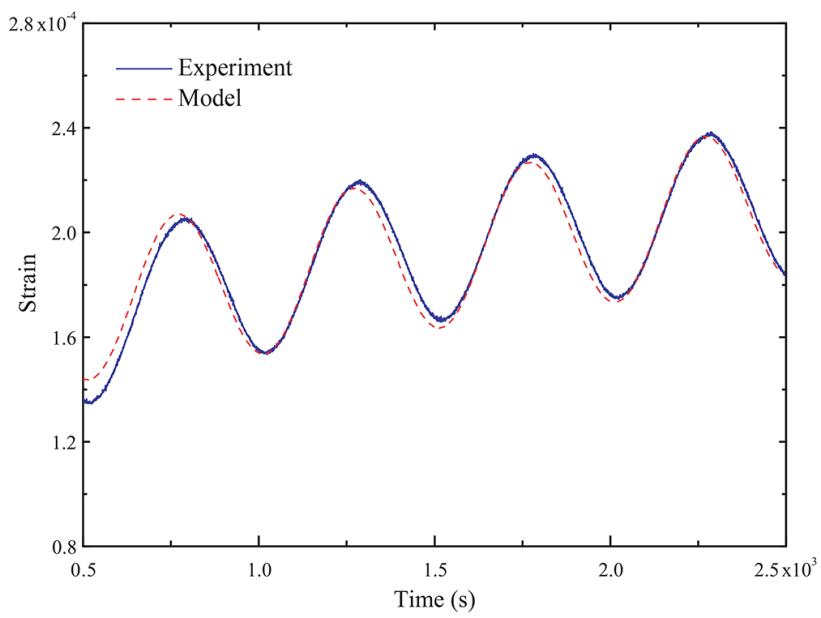

(e) $T=500 \mathrm{~s}$

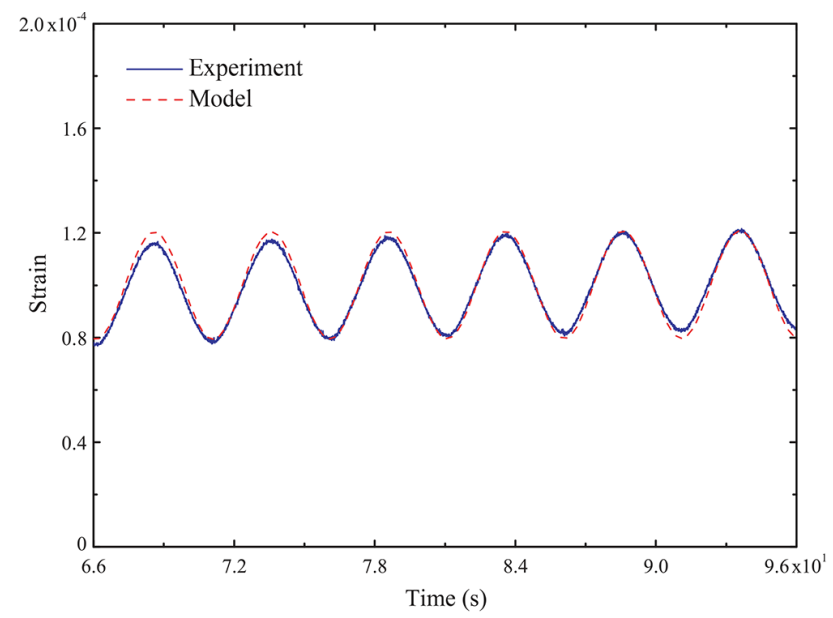

(b) $T=5 \mathrm{~s}$

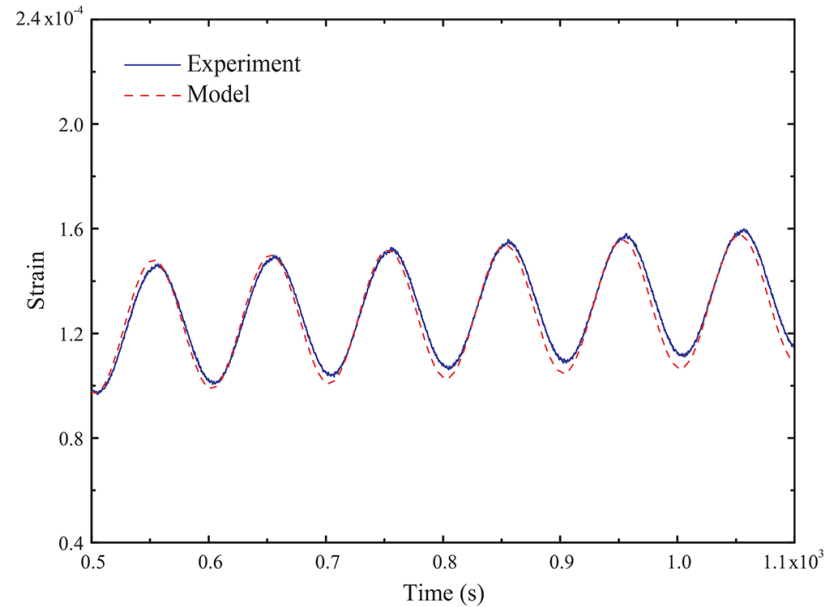

(d) $T=100 \mathrm{~s}$

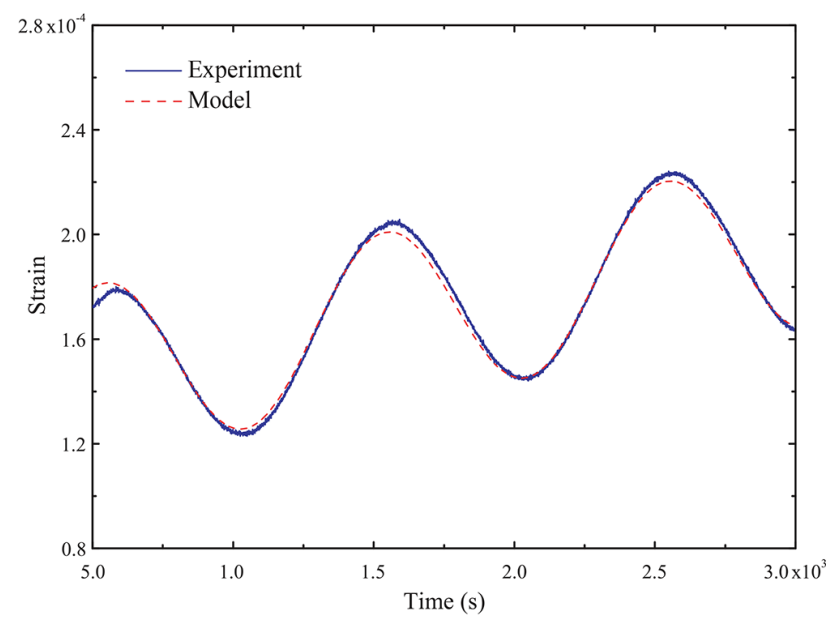

(f) $T=1000 \mathrm{~s}$

Figure 12. Comparison between the experimentally measured strain-time curves (in the steady stage) and the results yielded by the physically based model for specimen Dry-5pt-1, tested with stresses varying from 0.08 to $0.25 \mathrm{MPa}$ and with a temperature of $-10^{\circ} \mathrm{C}$. 
Table 4. Values of the model parameters calibrated for simulating the strain response of the ice specimens (in Sect. 5, these values are discussed and compared to those reported in the references).

\begin{tabular}{lrrrr}
\hline $\begin{array}{l}\text { Specimen } \\
\text { no. }\end{array}$ & $\begin{array}{r}\text { Elastic modulus } \\
E_{0}(\mathrm{GPa})\end{array}$ & $\begin{array}{r}\text { Dislocation density } \\
\rho\left(\mathrm{m}^{-2}\right)\end{array}$ & $\begin{array}{r}\text { Strength of dislocation } \\
\text { relaxation } \delta D^{\mathrm{d}}\left(\mathrm{Pa}^{-1}\right)\end{array}$ & $\begin{array}{r}\text { Strength of grain } \\
\text { boundary } \delta D^{\mathrm{gb}}\left(\mathrm{Pa}^{-1}\right)\end{array}$ \\
\hline Dry-5ppt-1 & 6.0 & $7.53 \times 10^{8}$ & $7 \times 10^{-10}$ & $1 \times 10^{-10}$ \\
Dry-5ppt-2 & 5.6 & $4.31 \times 10^{8}$ & $4 \times 10^{-10}$ & $1 \times 10^{-10}$ \\
Dry-7ppt-1 & 4.0 & $1.18 \times 10^{9}$ & $1.1 \times 10^{-9}$ & $1 \times 10^{-10}$ \\
Dry-7ppt-2 & 4.0 & $1.83 \times 10^{9}$ & $1.7 \times 10^{-9}$ & $3 \times 10^{-10}$ \\
Floating-5ppt-1 & 2.0 & $5.92 \times 10^{9}$ & $5.5 \times 10^{-9}$ & $3 \times 10^{-10}$ \\
Floating-5ppt-2 & 1.9 & $6.46 \times 10^{9}$ & $6 \times 10^{-9}$ & $1 \times 10^{-10}$ \\
Floating-7ppt-1 & 1.9 & $2.58 \times 10^{10}$ & $2.4 \times 10^{-8}$ & $3 \times 10^{-10}$ \\
Floating-7ppt-2 & 1.7 & $1.40 \times 10^{10}$ & $1.3 \times 10^{-8}$ & $2 \times 10^{-10}$ \\
\hline
\end{tabular}
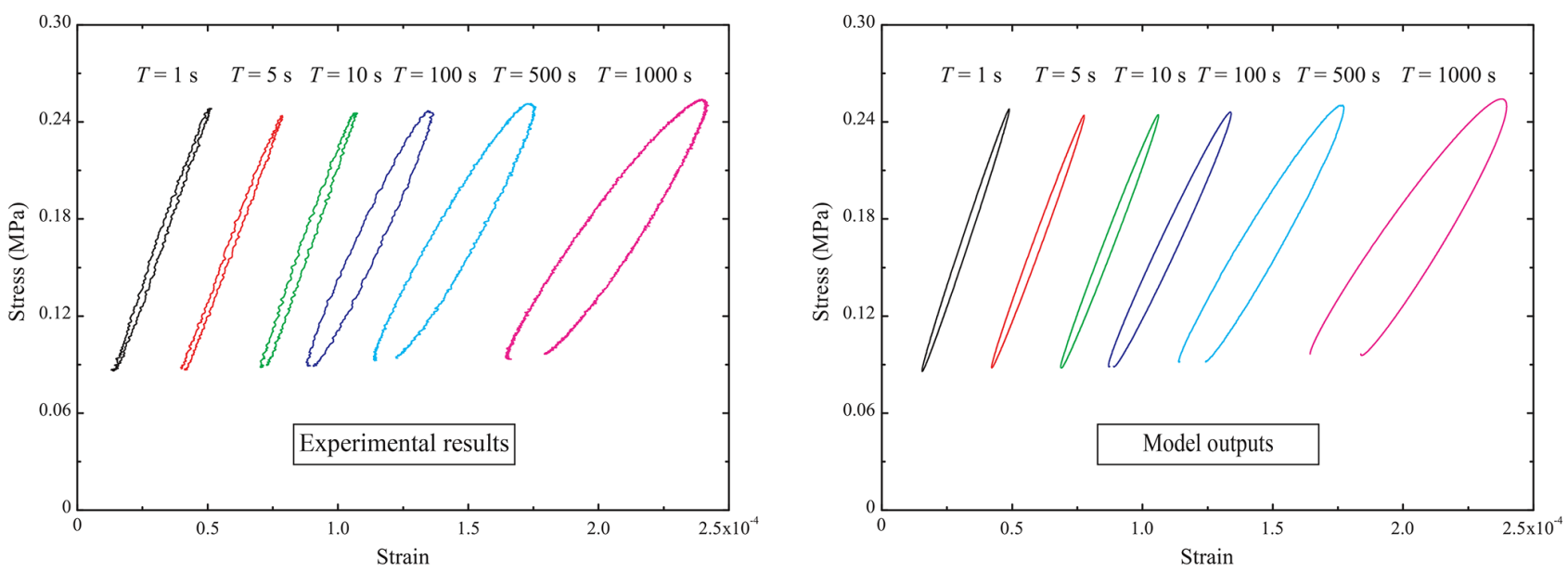

(a)
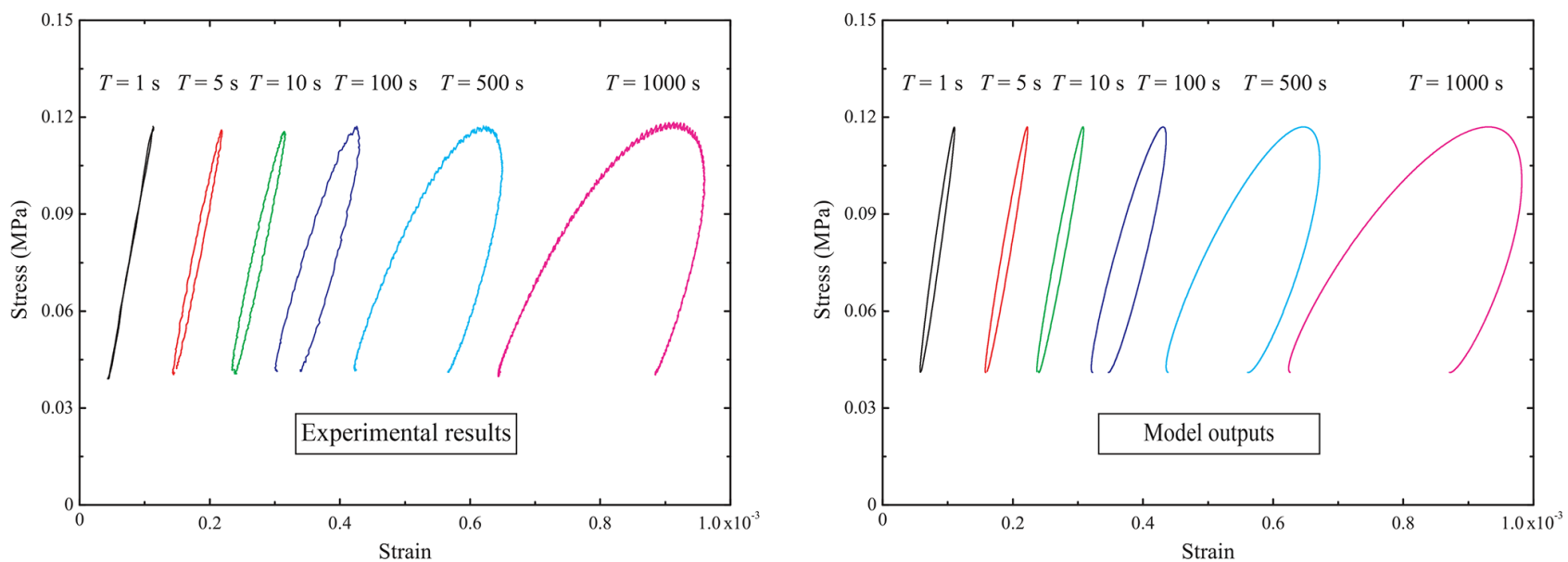

(b)

Figure 13. Comparison between the steady-state stress-strain hysteresis loop measured in the experiments and that outputted from the model for (a) specimen Dry-5ppt-1 with a temperature of $-10^{\circ} \mathrm{C}$ and (b) specimen Floating-5ppt- 1 with an average temperature of $-2.5^{\circ} \mathrm{C}$ (note that, to compare the representative hysteresis loops in all the different-frequency experiments with those outputted by the model in a more concise and intuitive way, the prestrains before the hysteresis loops drawn here are not equal to the experimental values). 
Table 5. Modeling results of the strain energy density $\left(\mathrm{J} \mathrm{m}^{-3}\right)$ dissipated per loading-unloading cycle (the values given in parentheses are error percentages of model predictions relative to experimental results).

\begin{tabular}{lrrrrr}
\hline Specimen no. & \multicolumn{5}{c}{ Frequency } \\
\cline { 2 - 6 } & $0.001 \mathrm{~Hz}$ & $0.002 \mathrm{~Hz}$ & $0.01 \mathrm{~Hz}$ & $0.1 \mathrm{~Hz}$ & $0.2 \mathrm{~Hz}$ \\
\hline Dry-5ppt-1 & $9.12(3 \%)$ & $5.16(-5 \%)$ & $1.74(-13 \%)$ & $0.69(3 \%)$ & $0.68(-4 \%)$ \\
Dry-5ppt-2 & $5.22(-3 \%)$ & $3.10(6 \%)$ & $1.15(-27 \%)$ & $0.55(19 \%)$ & $0.33(-8 \%)$ \\
Dry-7ppt-1 & $15.1(5 \%)$ & $8.76(22 \%)$ & $2.65(-8 \%)$ & $0.86(-5 \%)$ & $0.79(20 \%)$ \\
Dry-7ppt-2 & $21.9(5 \%)$ & $12.5(-11 \%)$ & $6.44(-17 \%)$ & $2.00(-20 \%)$ & $1.97(-4 \%)$ \\
Floating-5ppt-1 & $27.0(8 \%)$ & $14.9(-3 \%)$ & $4.05(-15 \%)$ & $0.91(7 \%)$ & $0.73(16 \%)$ \\
Floating-5ppt-2 & $30.3(7 \%)$ & $16.8(4 \%)$ & $4.58(-4 \%)$ & $0.89(-2 \%)$ & $0.61(13 \%)$ \\
Floating-7ppt-1 & $125(-17 \%)$ & $68.5(1 \%)$ & $18.6(-8 \%)$ & $3.79(-2 \%)$ & $2.58(2 \%)$ \\
Floating-7ppt-2 & $65.4(3 \%)$ & $36.4(-5 \%)$ & $10.0(-15 \%)$ & $2.18(-9 \%)$ & $1.73(6 \%)$ \\
\hline
\end{tabular}

Table 6. Modeling results of the strain energy dissipation rate (\%) per loading-unloading cycle (the values given in parentheses are error percentages of model predictions relative to experimental results).

\begin{tabular}{lrrrrr}
\hline Specimen no. & \multicolumn{5}{c}{ Frequency } \\
\cline { 2 - 6 } & $0.001 \mathrm{~Hz}$ & $0.002 \mathrm{~Hz}$ & $0.01 \mathrm{~Hz}$ & $0.1 \mathrm{~Hz}$ & $0.2 \mathrm{~Hz}$ \\
\hline Dry-5ppt-1 & $49.2(19 \%)$ & $36.7(-9 \%)$ & $18.5(-16 \%)$ & $9.43(-4 \%)$ & $9.81(-1 \%)$ \\
Dry-5ppt-2 & $37.4(6 \%)$ & $25.9(14 \%)$ & $13.9(-21 \%)$ & $7.5(-14 \%)$ & $5.70(4 \%)$ \\
Dry-7ppt-1 & $53.1(-4 \%)$ & $41.3(11 \%)$ & $20.2(-6 \%)$ & $8.99(-18 \%)$ & $8.50(1 \%)$ \\
Dry-7ppt-2 & $51.3(-8 \%)$ & $38.9(-13 \%)$ & $25.7(-20 \%)$ & $12.6(-21 \%)$ & $13.9(-2 \%)$ \\
Floating-5ppt-1 & $87.8(-2 \%)$ & $77.1(1 \%)$ & $40.0(-10 \%)$ & $16.0(3 \%)$ & $14.0(19 \%)$ \\
Floating-5ppt-2 & $91.1(-4 \%)$ & $82.0(17 \%)$ & $45.1(-14 \%)$ & $17.6(1 \%)$ & $13.4(19 \%)$ \\
Floating-7ppt-1 & $86.4(-12 \%)$ & $77.4(-16 \%)$ & $59.9(-15 \%)$ & $34.0(6 \%)$ & $28.2(12 \%)$ \\
Floating-7ppt-2 & $94.5(7 \%)$ & $88.3(1 \%)$ & $52.9(-6 \%)$ & $23.8(-10 \%)$ & $20.5(1 \%)$ \\
\hline
\end{tabular}

\section{Discussion}

Although past laboratory-scale work has provided insight into the mechanical behavior of sea ice, the work has been mostly performed using relatively cold, dry and isothermal specimens. The results above indicate that more attention should be paid to the mechanical behavior of relatively warm floating ice with a naturally occurring temperature gradient. Here efforts were made to develop a relatively low-cost, convenient and useful approach for laboratory-scale floating-ice experiments and for preparing small-scale, saline columnar ice specimens. The thin sections (Figs. 4 and 5) indicated that the measures taken on the ice production guaranteed the generation of nonoriented columnar ice. Moreover, the thin sections showed that the molds used for specimen preparation do not influence the columnar ice microstructure. This is encouraging as molds are not often incorporated into growing sheets of nonoriented columnar ice. The use of molds in this way significantly simplified specimen preparation and resulted in accurate dimensions. The molds are especially effective in the experiments on floating-ice specimens: the specimens produced thus have proper dimensions, require no cutting, have a realistic temperature gradient and can be quickly transferred to the test basin, so brine loss is minimized.

The results above are in qualitative agreement with what would be expected for floating ice as, for example, floating specimens with a through-thickness thermal gradient and a mean temperature of $-2.5^{\circ} \mathrm{C}$ exhibit lower modulus and more pronounced inelastic deformation in comparison with dry specimens at $-10^{\circ} \mathrm{C}$, as would be expected based on full-scale observations of the effect of temperature on this property (Timco and Weeks, 2010; Cole, 2020). This gives confidence on the methods employed in the production and mechanical testing of the specimens. Further, the good agreement between the results for floating ice and the corresponding model predictions shows quantitative validity of the approach taken here. All in all, the results suggest that the chosen experimental techniques (including the loading system, the strain measurement scheme, the data acquisition system and settings) worked well and provided useful results for the analysis. An exception is some of the $1 \mathrm{~s}$ period experiments, which yielded strain responses with unexpected features; this is because the hysteresis loop areas are very small in size, making accurate measurements with the used setup challenging. This could be circumvented in future experiments by using techniques and devices with even higher precision and 

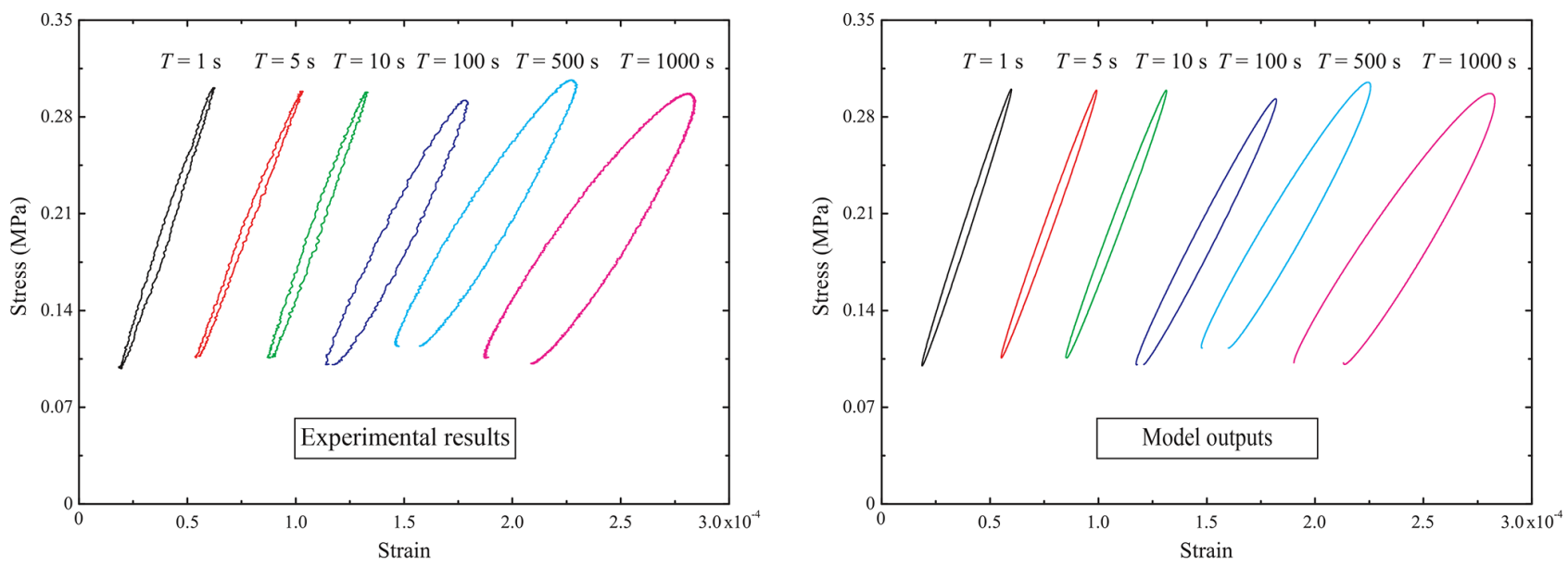

(a)
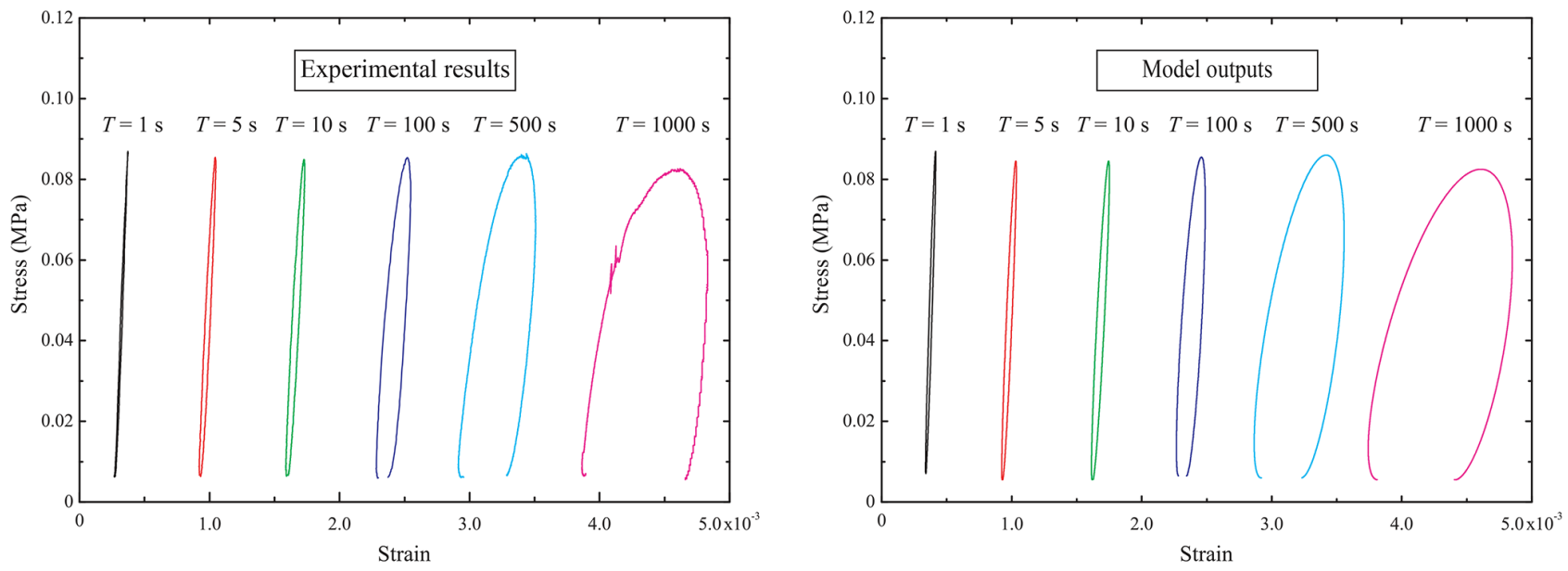

(b)

Figure 14. Comparison between the steady-state stress-strain hysteresis loops measured in the experiments and those predicted by the dislocation-based model for (a) specimen Dry-5ppt-1, tested with stresses varying from 0.1 to $0.3 \mathrm{MPa}$ and with a temperature of $-10{ }^{\circ} \mathrm{C}$, and (b) specimen Floating-5ppt-1, tested with stresses varying from 0.005 to $0.085 \mathrm{MPa}$ and with an average temperature of $-2.5^{\circ} \mathrm{C}$ (note that, to compare the representative hysteresis loops in all the different-frequency experiments with those outputted by the model in a more concise and intuitive way, the prestrains before the hysteresis loops drawn here are not equal to the experimental values).

setting a higher sampling rate of data acquisition. The methods proposed in this study to conduct laboratory experiments on floating-ice experiments are practical and can provide a convenient approach for relatively low-cost experimentation on floating ice.

The laboratory work here not only demonstrates the availability of the proposed experimental methods but also contributes to the understanding of the constitutive behavior of ice. A common trend in developing material models is to ensure they have a solid physical basis, that is, that they are based on an understanding of the physical processes that underlie the mechanical phenomena of interest. Above we used one such physically based model introduced by Cole (1995). Earlier work, which has been based on the experiments resembling the dry experiments here, has shown that the model is capable of predicting the inelastic deformation of sea ice via dislocation-based mechanisms and is able to estimate the effective dislocation density in ice from experimental results. Here the model was successfully validated against the results from the floating-ice experiments. Moreover, the results indicated that once the constant dislocation density value of the specimens was determined, the model adequately predicted the steady-stage deformation for the cyclic loading experiments conducted with different frequencies and stress levels. Even if the use of floating specimens could be considered to only address the temperature profiles of in situ floating ice (with some other environmental conditions of natural ice floes ignored), the above results bring confidence to the model and demonstrate its potential in modeling practical applications involving ice in such conditions, especially 
considering that some research has been launched to devote to a numerical implementation of the model (O'Connor et al., 2020).

The good agreement between the experimental and modeling results also motivates discussion on the parameter values in Table 4. Expectedly, the floating-ice specimens have lower unrelaxed moduli than the dry specimen. For the 5 and $7 \mathrm{ppt}$ saline ice, the average elastic modulus of the floating specimens is $66 \%$ and $55 \%$ lower than that of the dry specimens, respectively. In the dry experiments, the isothermal 7 ppt saline ice has a $31 \%$ lower average elastic modulus than the $5 \mathrm{ppt}$ saline ice. In the floating-ice experiments, the $7 \mathrm{ppt}$ saline specimen still has a lower average elastic modulus than the $5 \mathrm{ppt}$ saline specimen, but the difference, $8 \%$, is not as prominent as in the dry experiments. Thus, the fact that the floating ice had a realistic temperature profile had a larger influence on the elastic modulus of ice than the variation in the ice salinities studied here.

Table 4 also indicates that the dislocation densities determined for the ice specimens were on the order of $\sim 10^{8}-$ $10^{10} \mathrm{~m}^{-2}$ and thus were in good agreement with values on the order of $10^{9} \mathrm{~m}^{-2}$ given by Cole (1995). Moreover, the dislocation density of the floating ice was approximately 1 order of magnitude greater than that of the dry specimen. Note that there is precedent showing the dislocation density of ice increasing with temperature (Cole and Durell, 2001; Cole, 2020). The same trend is seen here when the experiments change from dry specimens $\left(-10^{\circ} \mathrm{C}\right)$ to relatively warm floating ones. In addition, the earlier work cited has shown that the dislocation density increases with the salinity. Therefore, the calculated dislocation densities make sense physically and are generally in line with expectations.

Specimens originating from two different ice sheets were tested. Table 4 shows that for a given set of conditions, the elastic modulus of the specimens showed only small variations from one sheet to another. Compared with the elastic modulus, the relative change in dislocation density was fairly large, which may be due to heterogeneity of ice. A similar degree of change in dislocation density was also reported by Cole and Durell (2001) and was related to dry isothermal ice specimens. As for the strength of the grain boundary relaxation, its value was taken as $2( \pm 1) \times 10^{-10} \mathrm{~Pa}^{-1}$ for all specimens since variations in grain size among the ice specimens were small. Thus, here the main quantity to be determined from the experimental results for studying anelastic strain response of the specimens was the dislocation density. It was also found that for relatively high loading frequency (for example, $1 \mathrm{~Hz}$ used here), the modeled strain behavior was dominated by the unrelaxed modulus $E_{0}$, not sensitive to the dislocation density or the strength of grain boundary relaxation. However, for low-frequency $(0.001 \mathrm{~Hz})$ cyclic loading, the modeled specimen deformation was very sensitive to the dislocation density.

The difference in the mechanical behavior between the floating and dry specimens has been mainly attributed to tem- perature (Golden et al., 2007). Moreover, the specimens harvested from floating ice sheets lose brine once removed from the sheet; warm ice in particular can lose a significant amount of brine, which could significantly alter the mechanical properties in subsequent experiments. In addition, some remaining brine (for example, in capillary brine channels) must freeze during the storage process of dry specimens; this may as well lead to some difference in the macroscopic mechanical behavior (for example, in elastic modulus) of dry and floating specimens (Marchenko and Lishman, 2017; Eicken, 1992; Jones et al., 2012; Gough et al., 2012). The methodology developed in the present effort avoids such problems and is expected to produce more realistic mechanical behavior, particularly when interest centers on behavior at relatively warm temperatures where brine drainage is extensive.

The analysis and modeling indicated that the physical mechanisms of deformation in both the warmer floating specimens and the colder dry specimens were essentially the same. Warmer saline ice had a smaller modulus due to its higher liquid brine volume, which necessarily decreases the volume of the solid ice matrix (thereby reducing the bulk elastic modulus), and there is a pronounced increase in effective dislocation density with increasing temperature (Cole and Durell, 2001; Timco and Weeks, 2010; Cole, 2020). Thus, according to Eq. (10), although the differences in ice temperature between the floating and dry experiments appear to result in an approximately twofold difference in the viscous component of strain, $\varepsilon_{\mathrm{v}}$, this does not mean that the temperature will make the viscous strain component of the floating ice only twice that of the dry ice. For example, the overall increase in strain for specimen Floating-5ppt-1 is much higher (15 times more) than that for specimen Dry-5ppt-1. This is mainly due to the aforementioned increase in effective dislocation density with increasing temperature (Cole and Durell, 2001; Cole, 2020).

\section{Conclusions}

Equipment and methods were developed to conduct laboratory experiments to examine the mechanical properties of floating saline ice specimens with a naturally occurring temperature gradient. In this initial effort, we examined the strain response of floating saline ice under cyclic compressive stresses and conducted reference experiments under dry, isothermal conditions. The experiments examined specimens having one of two nominal salinities (5 and $7 \mathrm{ppt}$ ); cyclic loading frequencies from $10^{-3}$ to $1 \mathrm{~Hz}$ were applied, and two levels of cyclic stress were applied. The experimental results compared favorably with the theoretical predictions obtained using a physically based constitutive model for saline ice. The following conclusions can be drawn.

Equipment and methods:

1. Groups of unaligned, columnar, grained saline ice specimens can be produced simultaneously in the laboratory 
using floating molds, and the presence of the molds has no observable effect on their microstructure.

2. The use of molds produced specimens that could be placed directly in the mechanical testing fixture, which for the case of floating-ice experiments provided a way to maintain a realistic temperature gradient during subsequent experimentation.

3. The experimental apparatus, which employed an electrohydraulic actuator and a saline water tank placed in a cold room, provided a way to apply in-plane loads to floating-ice specimens and successfully produced monotonic and cyclic loading waveforms employed in more conventional systems.

Constitutive modeling:

4. The dislocation mechanics of the model employed in the analysis can reproduce the strain response and energy dissipation of saline ice subjected to cyclic loading for floating-ice or dry specimens and for the observed ice salinities well. The results show that the prediction errors of the energy density dissipation and the energy release rate are within $\approx 20 \%$.

5. For either dry or floating specimens, the higher the salinity of ice, the lower the modulus $\left(E_{0}\right)$ and the larger the dislocation density $(\rho)$. In addition, $E_{0}$ is much higher, and $\rho$ is far smaller for the dry specimens than for the floating specimens, provided other experimental variables are consistent.

This work makes it clear that the mechanical behavior of floating specimens of saline ice can be examined in the laboratory under a reasonable approximation of in situ conditions and with good efficiency. This capability opens the door to more sophisticated experimental work on saline ice under more realistic environmental conditions than previously possible.

Code and data availability. The code used for material modeling was written in MATLAB. Scripts used for analysis and more detailed information on the experimental results are available from the authors upon request.

Author contributions. AP, MW and DMC designed the study. MW and MP performed the experiments. MW, AP and DMC contributed to the interpretation of the results. MW, AP and DMC drafted the paper. All authors commented on the text.

Competing interests. The authors declare that they have no conflict of interest.
Acknowledgements. The authors thank the help from the technical staff of Aalto University, Department of Mechanical Engineering, and especially from Kari Kantola and Veijo Laukkanen.

Financial support. This research has been supported by the Academy of Finland (Ice Block Breakage: Experiments and Simulations, ICEBES; grant no. 309830).

Review statement. This paper was edited by Evgeny A. Podolskiy and reviewed by Andrew Mahoney and one anonymous referee.

\section{References}

Blockley, E. W. and Peterson, K. A.: Improving Met Office seasonal predictions of Arctic sea ice using assimilation of CryoSat-2 thickness, The Cryosphere, 12, 3419-3438, https://doi.org/10.5194/tc-12-3419-2018, 2018.

Boe, J. L., Hall, A., and Qu, X.: September sea-ice cover in the Arctic Ocean projected to vanish by 2100 , Nat. Geosci., 2, 341343, https://doi.org/10.1038/ngeo467, 2009.

Bond, P. E. and Langhorne, P. J.: Fatigue behavior of cantilever beams of saline ice, J. Cold Reg. Eng., 11, 99112, https://doi.org/10.1061/(ASCE)0887-381X(1997)11:2(99), 1997.

Cheng, S., Tsarau, A., Evers, K. U., and Shen, H.: Floe size effect on gravity wave propagation through ice covers, J. Geophys. Res.Oceans, 124, 320-334, https://doi.org/10.1029/2018JC014094, 2019.

Cole, D. M.: Reversed direct-stress testing of ice: Initial experimental results and analysis, Cold Reg. Sci. Technol., 18, 303-321, https://doi.org/10.1016/0165-232X(90)90027-T, 1990.

Cole, D. M.: A model for the anelastic straining of saline ice subjected to cyclic loading, Philos. Mag. A, 72, 231-248, https://doi.org/10.1080/01418619508239592, 1995.

Cole, D. M.: On the physical basis for the creep of ice: the high temperature regime, J. Glaciol., 66, 1-14, https://doi.org/10.1017/jog.2020.15, 2020.

Cole, D. M. and Dempsey, J. P.: Influence of scale on the constitutive behavior of sea ice, in: International Union of Theoretical and Applied Mechanics Symposium on Scaling Laws in Ice Mechanics and Ice Dynamics, pp. 251-264, Kluwer, Dordrecht, https://doi.org/10.1007/978-94-015-9735-7_22, 2001.

Cole, D. M. and Dempsey, J. P.: In situ sea ice experiments in McMurdo Sound: cyclic loading, fracture, and acoustic emissions, J. Cold Reg. Eng., 18, 155-174, https://doi.org/10.1061/(ASCE)0887-381X(2004)18:4(155), 2004.

Cole, D. M. and Durell, G. D.: The cyclic loading of saline ice, Philos. Mag. A, 72, 209-229, https://doi.org/10.1080/01418619508239591, 1995.

Cole, D. M. and Durell, G. D.: A dislocation-based analysis of strain history effects in ice, Philos. Mag. A, 81, 1849-1872, https://doi.org/10.1080/01418610108216640, 2001.

Cole, D. M., Johnson, R. A., and Durell, G. D.: Cyclic loading and creep response of aligned first-year sea ice, J. Geophys. Res. 103, 21751-21758, https://doi.org/10.1029/98JC01265, 1998. 
Dempsey, J. P.: Research trends in ice mechanics, Int. J. Solids Struct., 37, 131-153, https://doi.org/10.1016/S00207683(99)00084-0, 2000.

Dempsey, J. P., Adamson, R. M., and Mulmule, S. V.: Scale effects on the in-situ tensile strength and fracture of ice, Part II: First-year sea ice at Resolute, N.W.T. Int. J. Fract., 95, 347-366, https://doi.org/10.1023/A:1018650303385, 1999.

Dempsey, J. P., Cole, D. M., and Wang, S.: Tensile fracture of a single crack in first-year sea ice, Phil. Trans. R. Soc. A, 376, 20170346, https://doi.org/10.1098/rsta.2017.0346, 2018.

Eicken, H.: Salinity profiles of Antarctic sea ice: Field data and model results, J. Geophys. Res.-Oceans, 97, 15545-15557, https://doi.org/10.1029/92JC01588, 1992.

Feltham, D. L.: Sea Ice rheology, Annu. Rev. Fluid Mech., 40, 91112, https://doi.org/10.1146/annurev.fluid.40.111406.102151, 2008.

Gagne, M. E., Gillett N. P., and Fyfe, J. C.: Observed and simulated changes in Antarctic sea ice extent over the past 50 years, Geophys. Res. Lett., 42, 90-95, https://doi.org/10.1002/2014GL062231, 2015.

Golden, K. M., Eicken, H., Heaton, A. L., Miner, J., Pringle, D. J., and Zhu, J.: Thermal evolution of permeability and microstructure in sea ice, Geophys. Res. Lett., 34, L16501, https://doi.org/10.1029/2007GL030447, 2007.

Gough, A. J., Mahoney, A. R., Langhorne, P. J., Williams, M. J. M., and Haskell, T. G.: Sea ice salinity and structure: A winter time series of salinity and its distribution, J. Geophys. Res.-Oceans, 7, C03008, https://doi.org/10.1029/2011JC007527, 2012.

Gow, A. J. Crystalline structure of urea ice sheets used in modeling experiments in the CRREL test basin, CRREL report, 8424, available at: https://hdl.handle.net/11681/9553 (last access: 10 January 2020), 1984.

Haskell, T. G., Robinson, W. H., and Langhorne, P. J.: Preliminary results from fatigue tests on in situ sea ice beams, Cold Reg. Sci. Technol., 24, 167-176, https://doi.org/10.1016/0165232X(95)00015-4, 1996.

Heijkoop, A. N., Nord, T. S., and Høyland, K. V.: Strain-controlled cyclic compression of sea ice, 24th IAHR International Symposium on Ice Vladivostok, Russia, 4 to 9 June 2018.

Herman, A., Cheng, S., and Shen, H. H.: Wave energy attenuation in fields of colliding ice floes - Part 1: Discrete-element modelling of dissipation due to ice-water drag, The Cryosphere, 13, 28872900, https://doi.org/10.5194/tc-13-2887-2019, 2019a.

Herman, A., Cheng, S., and Shen, H. H.: Wave energy attenuation in fields of colliding ice floes - Part 2: A laboratory case study, The Cryosphere, 13, 2901-2914, https://doi.org/10.5194/tc-13-29012019, 2019b.

Iliescu, D. and Schulson, E. M.: Brittle compressive failure of ice: monotonic versus cyclic loading, Acta Mater., 50, 2163-2172, https://doi.org/10.1016/S1359-6454(02)00060-5, 2002.

Iliescu, D., Murdza, A., Schulson, E. M., and Renshaw, C. E.: Strengthening ice through cyclic loading, J. Glaciol., 63, 663669, https://doi.org/10.1017/jog.2017.32, 2017.

Jones, K. A., Ingham, M., and Eicken, H.: Modeling the anisotropic brine microstructure in first-year arctic sea ice, J. Geophys. Res.Oceans, 117, C02005, https://doi.org/10.1029/2011JC007607, 2012.
Kartashkin, B. D.: Experimental studies of the physico-mechanical properties of ice, Tsentra'nyy Aerogidrodinamicheskiy Institut, Trudy 607, 1947

Kern, S., Lavergne, T., Notz, D., Pedersen, L. T., Tonboe, R. T., Saldo, R., and Sørensen, A. M.: Satellite passive microwave sea-ice concentration data set intercomparison: closed ice and ship-based observations, The Cryosphere, 13, 32613307, https://doi.org/10.5194/tc-13-3261-2019, 2019.

Langhorne, P. J., Squire, V. A., Fox, C., and Haskell, T. G.: Breakup of sea ice by ocean waves, Ann. Glaciol., 27, 438-442, https://doi.org/10.3189/S0260305500017869, 1998.

Langhorne, P. J., Hughes, K. G., Gough, A. J., Smith, I. J., Williams, M. J. M., Robinson, N. J., Stevens, C. L., Rack, W., Price, D., Leonard, G. H., Mahoney, A. R., Haas, C., and Haskell, T. G.: Observed platelet ice distributions in Antarctic sea ice: An index for ocean-ice shelf heat flux, Geophys. Res. Lett., 42, 54425451, https://doi.org/10.1002/2015GL064508, 2015.

Langway, C. C.: Ice fabrics and the universal stage, Report \# 62, CRREL, 1958.

Leclair, E. S., Schapery, R. A., and Dempsey, J. P.: A broad-spectrum constitutive modeling technique applied to saline ice, Int. J. Fract., 97, 209-226, https://doi.org/10.1023/A:1018358923672, 1999.

Li, J., Kohout, A. L., and Shen, H. H.: Comparison of wave propagation through ice covers in calm and storm conditions, Geophys. Res. Lett., 42, 5935-5941, https://doi.org/10.1002/2015GL064715, 2015.

Li, Z. and Riska, K.: Preliminary study of physical and mechanical properties of model ice, Technical Report M-212, Helsinki University of Technology, Espoo, Finland, 1996.

Liu, Y., Dai, F., Fan, P., Xu, N., and Dong, L.: Experimental investigation of the influence of joint geometric configurations on the mechanical properties of intermittent jointed rock models under cyclic uniaxial compression, Rock Mech. Rock Eng., 50, 4531471, https://doi.org/10.1007/s00603-017-1190-6, 2017.

Liu, Y., Dai, F., Dong, L., Xu, N., and Feng, P.: Experimental investigation on the fatigue mechanical properties of intermittently jointed rock models under cyclic uniaxial compression with different loading parameters, Rock Mech. Rock Eng., 51, 47-68, https://doi.org/10.1007/s00603-017-1327-7, 2018.

Lu, W. and Løset, S.: Parallel channels' fracturing mechanism during ice management operations. Part II: Experiment, Cold Reg. Sci. Technol., 156, 117-133, https://doi.org/10.1016/j.coldregions.2018.07.011, 2018.

Lu, W., Lubbad, R., Shestov, A., and Løset, S.: Parallel channels' fracturing mechanism during ice management operations, Part I: Theory, Cold Reg. Sci. Technol., 156, 102-116, https://doi.org/10.1016/j.coldregions.2018.07.010, 2018.

Marchenko, A. and Lishman, B.: The influence of closed brine pockets and permeable brine channels on the thermo-elastic properties of saline ice, Phil. Trans. R. Soc. A, 375, 20150351, https://doi.org/10.1098/rsta.2015.0351, 2017.

Mellor, M. and Cole, D.: Cyclic loading and fatigue in ice, Cold Reg. Sci. Technol., 4, 41-53, https://doi.org/10.1016/0165232X(81)90029-X, 1981.

Murdza, A., Schulson, E. M., and Renshaw, C. E.: Hysteretic behavior of freshwater ice under cyclic loading: A preliminary results, 24th IAHR International Symposium on Ice, Vladivostok, 185192, 2018. 
Murdza, A., Schulson, E. M., and Renshaw, C. E.: The effect of cyclic loading on the flexural strength of columnar freshwater ice, Proceedings of the 25th International Conference on Port and Ocean Engineering under Arctic Conditions (POAC'19), Delft, Netherlands, 2019.

O'Connor, D. T., West, B. A., Haehnel, R. B., AsenathSmith, E., and Cole, D.: A viscoelastic integral formulation and numerical implementation of an isotropic constitutive model of saline ice, Cold Reg. Sci. Technol., 171, 102983, https://doi.org/10.1016/j.coldregions.2019.102983, 2020.

Polojärvi, A., Tuhkuri, J., and Pustogvar, A.: DEM simulations of direct shear box experiments of ice rubble: Force chains and peak loads, Cold Reg. Sci. Technol., 116, 12-23, https://doi.org/10.1016/j.coldregions.2015.03.011, 2015.

Ranta, J., Polojärvi, A., and Tuhkuri, J.: The statistical analysis of peak ice loads in a simulated ice-structure interaction process, Cold Reg. Sci. Technol., 133, 46-55, https://doi.org/10.1016/j.coldregions.2016.10.002, 2017.

Ranta, J., Polojärvi, A., and Tuhkuri, J.: Ice loads on inclined marine structures - Virtual experiments on ice failure process evolution, Mar. Struct., 57, 72-86, https://doi.org/10.1016/j.marstruc.2017.09.004, 2018a.

Ranta, J., Polojärvi, A., and Tuhkuri, J.: Limit mechanisms for ice loads on inclined structures: Buckling, Cold Reg. Sci. Technol., 147, 34-44, https://doi.org/10.1016/j.coldregions.2017.12.009, 2018 b.

Reistad, M., Breivik, Ø., Haakenstad, H., Aarnes, O. J., Furevik, B. R., and Bidlot, J. R.: A high-resolution hindcast of wind and waves for the North Sea, the Norwegian Sea, and the Barents Sea, J. Geophys. Res., 116, C05019, https://doi.org/10.1029/2010JC006402, 2011.

Ridley, J. K. and Blockley, E. W.: Brief communication: Solar radiation management not as effective as $\mathrm{CO}_{2}$ mitigation for Arctic sea ice loss in hitting the 1.5 and $2{ }^{\circ} \mathrm{C} \mathrm{COP}$ climate targets, The Cryosphere, 12, 3355-3360, https://doi.org/10.5194/tc-12-33552018, 2018.

Schulson, E. M. and Duval, P.: Creep and fracture of ice, Cambridge University Press, Cambridge, 2009.
Serreze, M. C. and Stroeve, J.: Arctic sea ice trends, variability and implications for seasonal ice forecasting, Phil. Trans. R. Soc. A, 373, 20140159, https://doi.org/10.1098/rsta.2014.0159, 2015.

Smith, I. J., Gough, A. J., Langhorne, P. J., Mahoney, A. R., Leonard, G. H., Van Hale, R., Jendersie, S., and Haskellf, T. G.: First-year land-fast Antarctic sea ice as an archive of ice shelf meltwater fluxes, Cold Reg. Sci. Technol., 113, 63-70, https://doi.org/10.1016/j.coldregions.2015.01.007, 2015.

Tabata, T. and Nohguchi, Y.: Failure of sea ice by repeated compression, in: Physics and Mechanics of Ice, edited by: Tryde, P., International Union of Theoretical and Applied Mechanics, Springer, Berlin, Heidelberg, 351-362, https://doi.org/10.1007/978-3-64281434-1_25, 1980.

Timco, G. W. and Weeks, W. F.: A review of the engineering properties of sea ice, Cold Reg. Sci. Technol., 60, 107-129, https://doi.org/10.1016/j.coldregions.2009.10.003, 2010.

Tuhkuri, J. and Polojärvi, A.: A review of discrete element simulation of ice-structure interaction, Phil. Trans. R. Soc. A, 376, 20170335, https://doi.org/10.1098/rsta.2017.0335, 2018.

Vincent, M. R. and Dempsey, J. P.: Servo-hydraulic pin loading device (HPLD) for in situ ice testing, J. Cold Reg. Eng., 13, 21-36, https://doi.org/10.1061/(ASCE)0887381X(1999)13:1(21), 1999.

Voermans, J. J., Babanin, A. V., Thomson, J., Smith, M. M., and Shen, H. H.: Wave attenuation by sea ice turbulence, Geophys. Res. Lett., 46, 6796-6803, https://doi.org/10.1029/2019GL082945, 2019.

Weber, L. J. and Nixon, W. A.: Hysteretic behavior in ice under fatigue loading, Proceedings of the 15th International Conference on Offshore Mechanics and Arctic Engineering, 4, 75-82, 1996.

Wongpan, P., Hughes, K. G., Langhorne, P. J., and Smith, I. J.: Brine Convection, temperature fluctuations, and permeability in winter Antarctic land-fast sea ice, J. Geophys. Res.-Oceans, 123, 216230, https://doi.org/10.1002/2017JC012999, 2018.

Zijlema, M., van Vledder, G. Ph., and Holthuijsen, L. H.: Bottom friction and wind drag for wave models, Coast. Eng., 65, 19-26, https://doi.org/10.1016/j.coastaleng.2012.03.002, 2012. 